OPEN ACCESS

Edited by:

Diane C. Bassham,

lowa State University, United States

Reviewed by:

Stephen H. Howell,

Iowa State University, United States

Ismail Turkan,

Ege University, Turkey

*Correspondence:

Xiaofang $\mathrm{Li}$

xfl@bio.ecnu.edu.cn

${ }^{\dagger}$ Present address:

Xinghua Shao,

Renji Hospital, Shanghai Jiao Tong

University School of Medicine,

Shanghai, China

¥These authors have contributed equally to this work.

Specialty section:

This article was submitted to

Plant Cell Biology,

a section of the journal

Frontiers in Plant Science

Received: 16 November 2017 Accepted: 01 March 2018 Published: 16 March 2018

Citation:

Guo K, Wang W, Fan W, Wang Z, Zhu $M$, Tang $X, W u W$, Yang $X$, Shao $X$, Sun $Y$, Zhang $W$ and $L i X$ (2018) Arabidopsis GAAP1 and GAAP3 Modulate the Unfolded Protein Response and the Onset of Cell Death in Response to ER

Stress. Front. Plant Sci. 9:348. doi: 10.3389/fpls.2018.00348

\section{Arabidopsis GAAP1 and GAAP3 Modulate the Unfolded Protein Response and the Onset of Cell Death in Response to ER Stress}

\author{
Kun Guo $\neq$ Wei Wang $\neq$, Weiwei Fan, Zhiying Wang, Manli Zhu, Xiaohan Tang, \\ Wenting Wu, Xue Yang, Xinghua Shao', Yue Sun, Wei Zhang and Xiaofang Li*
}

School of Life Sciences, East China Normal University, Shanghai, China

The function of human Golgi antiapoptotic proteins (GAAPs) resembles that of BAX inhibitor-1, with apoptosis inhibition triggered by intrinsic and extrinsic stimuli. However, little is known about the function of GAAP-related proteins in plants. Here, we studied Arabidopsis GAAP1 and GAAP3 and found that they were localized on the cellular membrane, including the endoplasmic reticulum (ER) membrane. The function of GAAP1/GAAP3 in ER-stress response was tested, and results showed that single or double mutation in GAAP1 and GAAP3 reduced plant survival and enhanced cell death under ER stress. The expression of both genes was induced by various abiotic stress signals. Quantitative real-time polymerase chain reaction analysis showed that GAAP1/GAAP3 level affected the expression pattern of the unfolded-protein response (UPR) signaling pathway genes upon prolonged ER stress. The mutation in both GAAP1 and GAAP3 genes promoted and enhanced UPR signaling when confronted with mild ER stress. Moreover, GAAP1/GAAP3 inhibited cell death caused by ER stress and promoted plant-growth recovery by turning down inositol-requiring enzyme 1 (IRE1) signaling after ER stress had been relieved. Co-immunoprecipitation (Co-Ip) and BiFC assays showed that GAAP1/GAAP3 interacted with IRE1. These data suggested that GAAP1/GAAP3 played dual roles in the negative regulation of IRE1 activity and anti-programmed cell death.

Keywords: Arabidopsis thaliana, GAAP, ER stress, IRE1, cell death, unfolded-protein response

\section{INTRODUCTION}

The endoplasmic reticulum (ER) is highly sensitive to physiological conditions or environmental stimuli. ER stress generally occurs when unfolded or misfolded proteins aggregate or when the load of client proteins exceed the folding capacity of the ER, which is caused by many adverse abiotic and biotic conditions. Pharmacologic agents such as tunicamycin (TM), an inhibitor of $N$-linked glycosylation, and dithiothreitol (DTT), a redox reagent, are widely used to induce ER

Abbreviations: $\mathrm{Bax}, \mathrm{Bcl}-2$ associated $\mathrm{X}$ protein; $\mathrm{BiFC}$, bimolecular fluorescence complementation; $\mathrm{DAB}, 3$, 3'-diaminobenzidine; DTT, dithiothreitol; ER, endoplasmic reticulum; FDA, fluorescein diacetate; GUS, beta-D-glucuronidase; PCD, programmed cell death; PI, propidium iodide; qRT-PCR, quantitative real-time PCR; ROS, reactive oxygen species; TM, tunicamycin; UPR, unfolded protein response. 
stress in the laboratory (Yang et al., 2016). When facing ER stress, cells activate the unfolded-protein response (UPR) to address the problem. In mammalian cells, three UPR signaling pathways are initiated by ER transmembrane receptors, namely, inositol-requiring enzyme 1 (IRE1), protein kinase RNA-activated-like ER kinase (PERK), and activating transcription factor 6 (ATF6), to promote cell survival by restoring ER homeostasis (Walter and Ron, 2011; Brewer, 2014). Except for PERK ortholog, UPR pathways mediated by IRE1 and ATF6 homologs have been identified in plants (e.g., the IRE1 and bZIP28 pathways in Arabidopsis) (Liu et al., 2007; Deng et al., 2011; Nagashima et al., 2011; Humbert et al., 2012). IRE1 acts by splicing messenger RNA encoding transcription factor $\mathrm{XBP} 1$ in mammalian cell or bZIP60 in plant cell, respectively, to upregulate genes encoding factors that aid in protein folding and degradation (Nagashima et al., 2011; Iwata and Koizumi, 2012). Activated IRE1 also cleaves and degrades some mRNAs that reduce protein loading in the ER (Mishiba et al., 2013). NAC103 has been identified as the direct target of the spliced bZIP60 and relays ER stress signals to UPR downstream genes (Sun et al., 2013). Similar to ATF6, Arabidopsis bZIP28 transports to the Golgi and undergoes regulated intramembrane proteolysis before moving into the nucleus to upregulate the expression of genes involved in various ER quality-control processes under ER stress (Haze et al., 1999; Liu et al., 2007; Walter and Ron, 2011). However, if ER stress is severe and the cytoprotective outcomes are insufficient to restore ER homeostasis, the UPR triggers cell-death program to kill ER stress cells (Ogawa and Mori, 2004; Lin et al., 2007; Dai et al., 2016). In mammalian cells, IRE1 exhibits different activities or functions depending on various partner proteins. For example, the association of the BCL-2 family members BAX and BAK with the cytosolic domain of IRE $1 \alpha$ regulates the initiation and duration of IRE1 $\alpha$ adaptive activity (Hetz and Glimcher, 2009; Woehlbier and Hetz, 2011; Hetz, 2012). Meanwhile, BAX inhibitor-1 (BI-1) interacts with IRE1 $\alpha$ and negatively regulates its activity (Lisbona et al., 2009). Under irreversible ER stress, IRE1 $\alpha$ interacts with tumor necrosis factor receptor-associated factor 2 to promote cell death (Urano et al., 2000; Dhanasekaran and Reddy, 2008; Brewer, 2014; Zheng et al., 2017). Diminished IRE1 $\alpha$ activity, concomitant with ongoing PERK signaling, during prolonged ER stress may be pivotal in shifting the UPR toward a proapoptotic outcome (Lin et al., 2007, 2009). A growing body of evidence indicates that ER stress initiates UPR for cell survival and facilitates programmed cell death (PCD) under severe stress in plant. In Arabidopsis, the membrane transcription factor NAC089 is upregulated by bZIP28 and bZIP60 and activates downstream genes involved in PCD (Liu et al., 2007; Liu and Howell, 2010; Yang et al., 2014). However, little is known about how the activities of ER-stress sensors are regulated and how the different outcomes between cell survival and death effects can be determined in plants.

Genes that control PCD are conserved across wide evolutionary distances in metazoans (Lam, 2004). In mammals, ER-stress-induced cell death is a process controlled by the balance among various anti- and proapoptotic members of the BCL-2 protein family and antiapoptotic members of the BI-1 family (Lisbona et al., 2009; Flusberg and Sorger, 2015). Only BI-1 genes have been identified in plants to date. Similar to its homolog in mammals, plant BI-1 reportedly plays an important role as a survival factor under multiple stress conditions. However, plant BI-1 has little effect on UPR signaling under ER stress (Watanabe and Lam, 2008). Arabidopsis BI-1 has also been observed to attenuate the prosurvival function of bZIP28 during recovery from ER stress. Differently from animal cells, Arabidopsis BI-1 does not temper the ribonuclease activity of IRE1 under temporary ER stress (Ruberti et al., 2018). Six other BI-1-like proteins have been described, namely, transmembrane BAX inhibitor motif containing (TMBIM) $1-6$ and $1 \mathrm{~b}$, with BI-1 being TMBIM6 in mammals. Five of TMBIM members are also denoted together as Lifeguard (LFG) family according to a phylogenetic analysis (Hu et al., 2009; Carrara et al., 2012, 2017). TMBIM4 (LFG4), also known as Golgi antiapoptotic proteins (GAAPs) are highly conserved throughout eukaryotes (Gubser et al., 2007; Carrara et al., 2017). TMBIM4 was first identified in humans as h-GAAP, which most closely resembles BI-1, with apoptosis inhibition triggered by intrinsic and extrinsic stimuli. Arabidopsis thaliana GAAP1 (AT4G14730) was predicted to encode GAAP-related proteins through BLAST searches with h-GAAP (Gubser et al., 2007). Five GAAP gene members are found in Arabidopsis, and they are named AtLFG1-5 in another report. GAAP1/LFG1 and GAAP2 (At3g63310)/LFG2 proteins are further reportedly involved in modulating the interaction between plant and biotrophic powdery mildew fungi (Weis et al., 2013). However, whether Arabidopsis GAAPs have an evolutionarily conserved function in regulating PCD induced by abiotic stimuli remains unknown.

Here, we analyzed the cellular localization of GAAP1 and GAAP3 (At4g02690) in plant cells and their expression patterns. The two proteins resided on cellular membrane, including ER membrane. Both genes were expressed at very low levels during the seedling stage and induced by various stress signals. We found that GAAP1 and GAAP3 levels were critical to plant survival under ER stress. Molecular analysis further showed that the ectopic expression of GAAP1/GAAP3 delayed UPR activation, whereas mutation in both genes promoted and enhanced UPR signaling when confronted with mild ER stress. Moreover, GAAP1/GAAP3 inhibited cell death induced by ER stress and promoted plant-growth recovery by turning down UPR process mediated by IRE1 after the ER stress had been relieved. Co-immunoprecipitation (Co-IP) and BiFC assays showed that GAAP1/GAAP3 interacted with IRE1. All these data suggested that GAAP1/GAAP3 played dual roles in the regulation of UPR and PCD.

\section{MATERIALS AND METHODS}

\section{Plant Material and Growth Conditions}

Arabidopsis thaliana of ecotype Columbia-0 ( $\mathrm{Col}$ ) plants and T-DNA insertion mutants in the Col-0 background were used. The mutants gaap1-1 (Salk_046652c), gaap1-2(CS814417), and gaap3 (SALK_001992) were isolated from the Salk T-DNA collection. The T-DNA insertion site was confirmed by the 
polymerase chain reaction (PCR) amplification of plant genomic DNA with T-DNA primers and gene-specific primers. The double mutant gaap1gaap3 was generated by the hybridization of gaap 1-1 and gaap3. Seeds were stratified at $4^{\circ} \mathrm{C}$ for $2-3$ days before germination, and plants were grown under continuous white light at $23 \pm 2{ }^{\circ} \mathrm{C}$ in soil or on $1 / 2 \mathrm{MS}$ medium ( $1 \%$ sucrose, $0.8 \%$ agar).

To test the sensitivity of seedlings to ER stress, unless otherwise specified, 3-day-old seedlings grown on a filter paper placed on a 1/2 MS agar plate were transferred onto a plate containing different concentrations of TM or DTT for various times. To test growth recovery, 4-day-old seedlings that had been infiltrated with $1 / 2$ MS liquid salt containing $0.00,0.15$, and $1.00 \mu \mathrm{g} \mathrm{mL}^{-1} \mathrm{TM}$ for $6 \mathrm{~h}$ were transferred onto $1 / 2 \mathrm{MS}$ solid medium. The fresh weight of seedlings was determined during recovery time, and inhibition rate was calculated by the decrement divided by the control weight. All calculations were performed using data from three independent experiments.

For RT or qRT assay, unless specifically noted, 7-day-old seedlings were incubated with 1/2 MS liquid medium containing different concentrations of TM for the times indicated. A medium containing 0.1\% DMSO was used as control.

\section{Plasmid Construction}

The open reading frame of GAAP1 and GAAP3 gene was introduced into the binary vector pMon530 (Monsanto, United States) under the 35S-promoter respectively to generate GAAP1 and GAAP3 overexpression constructs.

To illustrate the cellular localization of GAAP1 and GAAP3, the C-terminal of both gene fusion to YFP, named as 35S::GAAP1-YFP and 35S::GAAP3-YFP, were constructed in the binary $\mathrm{pHB}$ vector (Luo et al., 2014). The N-terminal of both gene fusions to YFP was constructed in pMon530 vector to generate YFP-GAAP1 and YFP-GAAP3, respectively. The HDEL sequence is the ER location signal (Srivastava et al., 2013), and the ERmarker CFP tags with HDEL signal was prepared by amplifying CFP-HDEL and ligating it into pMon530.

To make promoter-GUS ( $\beta$-D-glucuronidase) constructs, genomic DNA sequences corresponding to 3600 bp upstream of the ATG codon of the GAAP1 ORF and 1041 bp promoter of GAAP3 were cloned into $\mathrm{pBI} 101.1$ vector, respectively.

For the BiFC assay, we fused the $\mathrm{N}$ - and $\mathrm{C}$-terminal halves of YFP to the N-terminus of GAAP1/GAAP3 and C-terminus of IRE1A encoding the kinase and endoribonuclease domains, respectively. The vectors of BiFC (pXY104 and pXY106) were used.

The primers pairs are listed in Supplementary Table S1, and all generated constructs were confirmed by sequencing.

\section{Plant Transformation and Transgenic Plant Analysis}

Agrobacterium tumefaciens strain GV3101 was used, and transformation was performed using the floral-dip method. The phenotypic effects of GAAP1 and GAAP3 in transgenic Col plants were analyzed in more than five independent transgenic lines. Transgenic plants carrying GAAP1::GUS and GAAP3::GUS were further selected for GUS activity detection as previously described (Li et al., 2009). Seedlings of GAAP1::GUS and GAAP3::GUS plants were incubated for 12 and $6 \mathrm{~h}$, respectively at $37^{\circ} \mathrm{C}$ in the staining buffer. The inflorescence organs of GAAP1::GUS and GAAP3::GUS were incubated 24 and for $12 \mathrm{~h}$ respectively.

Transient-expression experiments were performed as previously described (Sparkes et al., 2006). The tag-fusion constructs were introduced into tobacco (Nicotiana clevelandii) leaf epidermal cells using the Agrobacterium tumefaciens-mediated infiltration technique.

\section{Protein Subcellular Localization and BiFC Assays}

Subcellular localization of the fluorescent proteins was determined by confocal laser scanning microscopy (Leica TCS SP5II). Fluorescing cells were imaged using a filter set with excitation wavelengths of 510 and $436 \mathrm{~nm}$, as well as emission filters at 517-540 and 488-490 nm, for YFP fusion and CFP fusion, respectively. For FM4-64 staining, roots of 4-day-old vertically grown seedlings were used and performed as previously reported (Bolte et al., 2004). Protein colocalization and BiFC assays were as previously described (Luo et al., 2014).

\section{Histochemistry and Microscopy}

Propidium iodide (PI) and fluorescein diacetate (FDA, Sigma-Aldrich) staining as fluorescent indicators of cell-membrane permeability and cell viability, respectively, were performed as previously described (Watanabe and Lam, 2008). Nuclei in root cells were stained using 4',6-diamidino2-phenylindole (DAPI; Sigma-Aldrich) at $0.5 \mu \mathrm{g} \mathrm{mL}^{-1}$ in $0.1 \%$ (v/v) Triton X-100 for $10 \mathrm{~min}$ and then washed twice with water. DAPI-stained nuclei were observed under a fluorescence microscope $($ excitation $=390 \mathrm{~nm}$; emission $=460 \mathrm{~nm})$. Cell death detection with trypan blue staining was performed as described (Duan et al., 2010; Leite et al., 1999; Ning et al., 2002). $\mathrm{H}_{2} \mathrm{O}_{2}$ was detected with an endogenous-peroxidase-dependent in situ histochemical staining procedure using 3,3'-diaminobenzidine (DAB) (Thordal-Christensen et al., 1997). Four to five biological replicates were conducted for each staining, and at least 20 samples were determined for each genotype every replicate.

\section{Ion Leakage Measurement}

The progression of cell death was assayed by measuring ion leakage from shoots after TM treatment. For each measurement, 20 shoots were immersed in $10 \mathrm{~mL}$ of distilled water with gentle shaking for $2 \mathrm{~h}$ at room temperature. The conductivity of the bathing solution was directly measured with a conductivity meter (METTLER TOLEDO SevenCompact S230). Measurements for each sample were performed at least in triplicate.

\section{Quantitative Real-Time Reverse-Transcription PCR (qPCR)}

Total RNA from different tissues was extracted from a frozen tissue using TRIZOL reagent (Invitrogen), and the first cDNA strand was generated according to the instructions for 
Superscript RT (Toyobo, Japan). qPCR analysis was performed with three to six independent biological replicates, and data were analyzed as previously reported (Schmittgen and Livak, 2008; Li et al., 2013). The relative UPR gene expression was the expression level of each gene in different genotype plants normalized to the level in the wild-type control, both of which were normalized to the expression of ACTIN8. The specific primers for each gene are listed in Supplementary Table S1. Two-way ANOVA was performed, and Tukey's range (honestly significant difference) test was used to determine significant differences among genotypes.

\section{Co-IP of Interacting Proteins}

For the Co-IP assay, the truncated form of IRE1A containing kinase and RNase domains (amino acids 375-881) was cloned into pCAMBIA1300-35S-X-TAP plasmid (Li et al., 2012) to produce a TAP fusion construct, IRE1A-KR-TAP. FLAG-epitope-tagged GAAP3 cDNA was cloned into pCAMBIA1300-35S-3 × FLAG vector (Li et al., 2012) at BamHI and SalI sites respectively. IRE1A-KR-TAP and FLAG-GAAP3 were co-transformed into tobacco leaves. Leaves about 2-3 days after transformation were ground in liquid nitrogen, and proteins were isolated as previously described (Iwata et al., 2008). We used anti-Flag M2 affinity gel (Sigma) to capture FLAG-tagged proteins following the manufacturer's instruction. Western blot was performed using the anti-FLAG M2 antibody and peroxidase-antiperoxidase soluble complex (Sigma).

\section{RESULTS}

\section{GAAP1 and GAAP3 Protein Localized on Membrane Including ER Membrane}

GAAP1 and GAAP3 are closely related proteins sharing strikingly similar sequences (53.4\% identity and $76.1 \%$ similarity). Similar to the secondary structure of mammalian GAAP protein, Arabidopsis GAAP1 and GAAP3 protein were also supposed to have seven transmembrane domains according to the prediction system $^{1}$. To determine the subcellular localization of GAAP1 and GAAP3, the ER marker CFP-HDEL was co-transformed with GAAP1-YFP or GAAP3-YFP in tobacco epidermal cells. The fluorescence signal of both GAAP1-YFP and GAAP3-YFP were found to be close to the membrane and cytoplasm. At least part of the fluorescence signal of both GAAP1-YFP and GAAP3-YFP was co-localization with the ER marker CFP-HDEL (Figures 1A,B). Additionally, the stable transgenic Arabidopsis plants transformed with YFP fused with the N-terminal of GAAP1 and GAAP3 constructors were obtained. Most of the fluorescence signals of YFP-GAAP1 or YFP-GAAP3 merged with FM4-64 dye in root cells (Figure 1C). FM464 is a membrane-selective fluorescent dye frequently used as a membrane and endosome marker (Bolte et al., 2004; Zonia and Munnik, 2008). These data suggested that both proteins were located on cellular membrane including ER membrane.

\footnotetext{
${ }^{1}$ http://harrier.nagahama-i-bio.ac.jp/sosui/sosui_submit.html
}

\section{GAAP1 and GAAP3 Preferentially Expressed in the Reproductive Organs}

To illustrate the expression patterns of GAAP1 and GAAP3, GUS staining in GAAP1/GAAP3::GUS transgenic Arabidopsis plants in addition to qRT-PCR or RT-PCR assay was performed. Results showed that GAAP1 was weakly expressed in young seedlings and exclusively expressed in the reproductive organs (Figures 2A-K). GAAP1 was expressed mainly at the tip of leaf primordium and young leaf during the seedling stage (Figures 2A-D,K). GAAP1::GUS activity and transcripts level were observed to be higher in flower buds and young siliques (Figures 2E-J). In flower bud, GUS signal was observed in the stamen and pistil (Figure 2E). With flower development, no GUS staining was found in the full-grown anther, but in the filament (Figures 2F-H). GUS activity was strong in the ovule during female megagameto genesis. With the fertilization onset, signals began to decrease from the chalazal pole to the micropylar pole. GUS staining was concentrated around the embryo and micropylar endosperm at the globular stage of embryo. By the time of the heart stage, signals were observed only at the site of micropylar pole (Figure 2J).

GAAP3 signal appeared during seed germination and was mainly expressed in the cotyledon and the root during the young-seedling stage (Figures 2L-N). GAAP3 expression in cotyledon weakened with seedling growth (Figures 2L,O,P). GAAP3 was highly expressed throughout the entire developmental stage of the anther and in the style after pollination in addition to silique (Figures 2Q-T).

\section{GAAP1 and GAAP3 Expression Levels Were Induced by Several Stress Signals}

The effects of TM or salt treatment on GAAP1 and GAAP3 expression during the seedling stage were tested. As shown in Figure 3A, GAAP1 transcripts did not change in seedlings before $6 \mathrm{~h}$ upon treatment with $0.5 \mu \mathrm{g} \mathrm{\textrm {mL } ^ { - 1 }} \mathrm{TM}$. The transcripts' level increased but not significantly with the progression of ER stress over $12 \mathrm{~h}$. Real-time PCR analysis also showed that the level of GAAP1 transcript in roots and leaves was up-regulated by chronic treatment with $\mathrm{TM}$ and $100 \mathrm{mmol} \mathrm{L}^{-1} \mathrm{NaCl}$ to some extent (Figure 3B). However, GAAP3 transcripts were up-regulated quickly and significantly by ER stress and salt stress in cotyledons, hypocotyls, and root tips assayed by qPCR and promoter-GUS reporter assay (Figures 3C-E). Furthermore, GAAP3 gene was not enhanced in gaap3 mutant upon TM treatment (Figure 3D).

\section{Mutations of GAAP1 and GAAP3 Enhanced the Plant Sensitivity to ER Stress}

To determine whether GAAP1 and GAAP3 can resist ER stress, we obtained loss-of-function mutant gaap1-1, gene knock-down mutants gaap1-2 and gaap3, and double mutant gaap1-1 gaap3 in addition to transgenic lines overexpressing GAAP1or GAAP3 in Col (Supplementary Figure S1). All mutants and transgenic plants did not exhibit obvious growth defects above ground when growing on soil under normal growth 

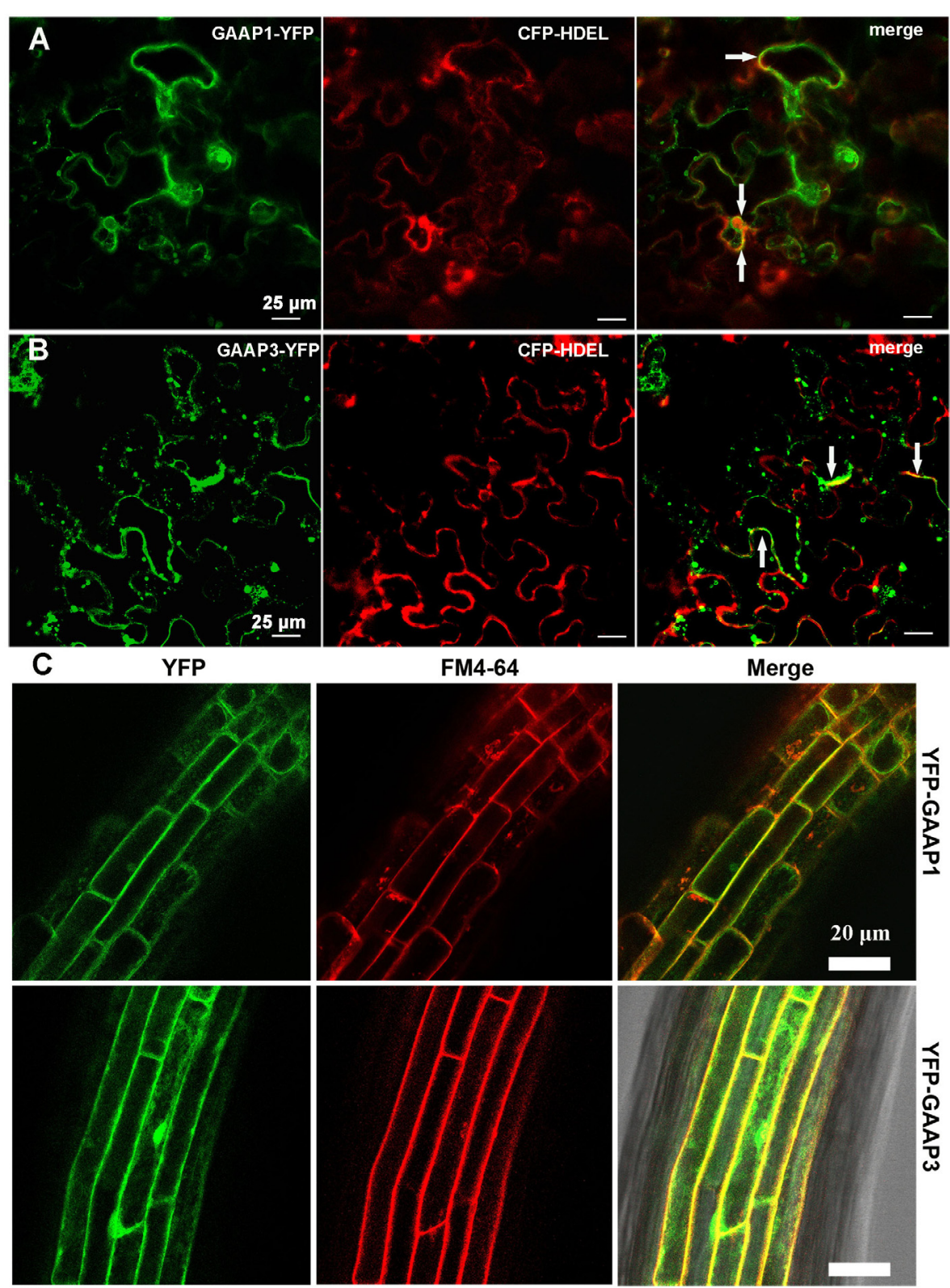

FIGURE 1 | GAAP1 and GAAP3 are located on cellular membrane including the ER.Observation of the fluorescence of GAAP1-YFP (A) and GAAP3-YFP

(B) co-transformed with ER marker CFP-HDEL in tobacco leaf epidermal cells. Yellow signals represent co-localization of two proteins, which are pointed by arrows.

(C) Fluorescence of YFP-GAAP1/GAAP3 merged with the membrane marker FM4-64 in the root cells of stable Arabidopsis transformants.

conditions. When seedlings were transferred to TM-containing (0.1-0.5 $\left.\mu \mathrm{g} \mathrm{mL}^{-1}\right)$ medium to grow for 7-10 days, plant survival decreased in a TM-dose-dependent manner (Figure 4). In terms of mortality rate and membrane permeability indicated by electrical conductivity, GAAP1/3 mutation reduced plant survival subjected to ER stress. GAAP1or GAAP3-overexpressing seedlings survived the best upon chronic TM damage, although the mortality rates of the transgenic plants insignificantly differed from Col. ER stress was also triggered by DTT. Similarly, when 4-day-old seedlings were transferred into the medium with $5 \mathrm{mmol} \mathrm{L}{ }^{-1}$ DTT, more severe growth inhibition was found earlier in gaap1-1 and gaap1gaap3 double mutants, and a higher death rate was observed in all mutants upon $5 \mathrm{mmol} \mathrm{L}^{-1}$ DTT for 10 days (Supplementary Figure S2). The double mutant gaap1gaap3 was generally the most sensitive, and gaap1-2 and gaap3 were slightly more sensitive than the wild-type based on the rate of healthy plants and mortality (Figure 4 and Supplementary Figure S2). To confirm that the T-DNA insertion in gaap1-1 and gaap3 was in fact responsible for the sensitivity defects, we transformed 35S::GAAP1 into gaap1-1 mutant and GAAP3 driven by its native promoter into gaap3 mutant respectively and found that the sensitivity 

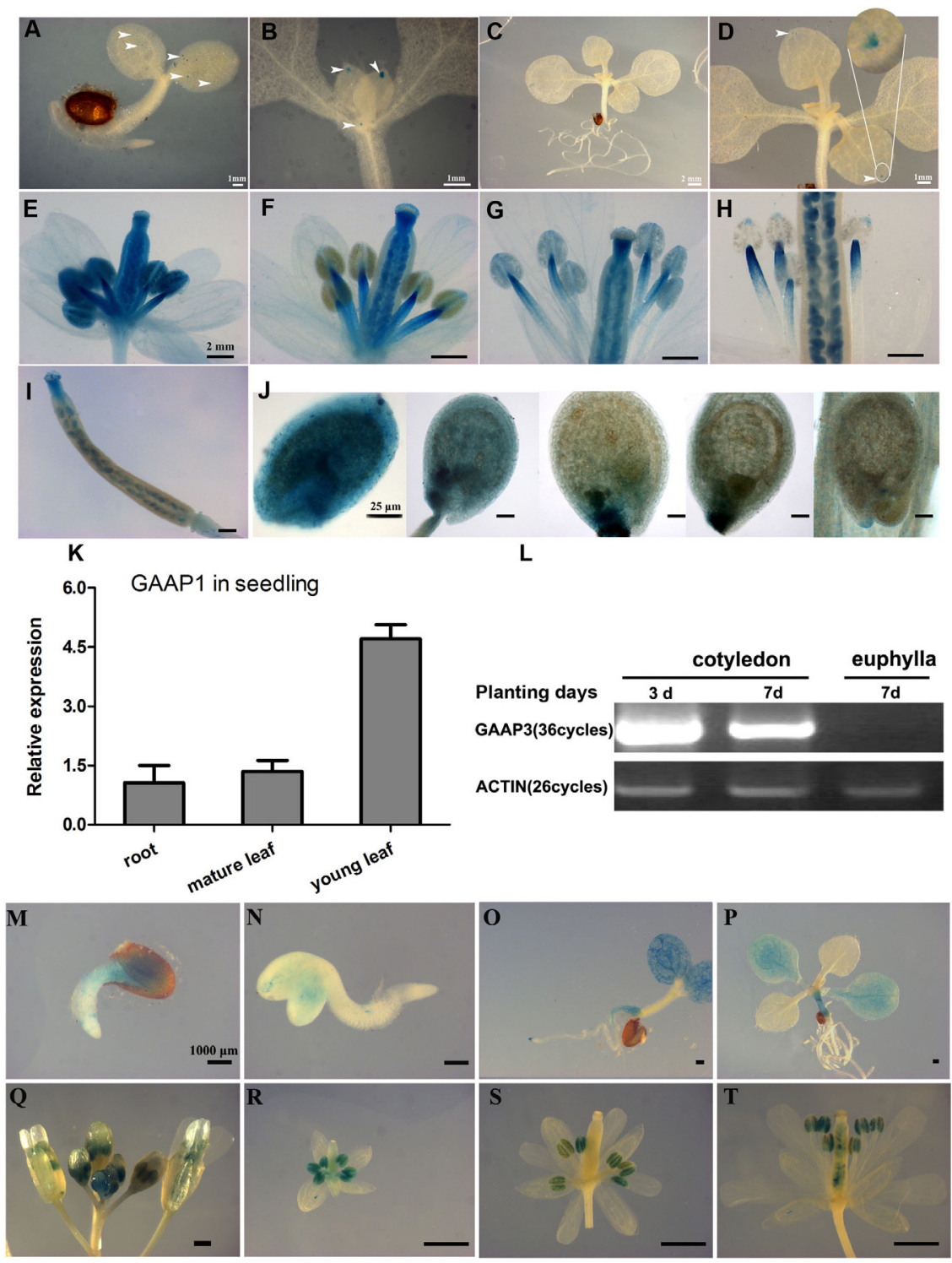

FIGURE 2 | Expression patterns of GAAP1 and GAAP3 in Arabidopsis. GUS staining of GAAP1 in 3-day-old seedling (A), in the above-ground area of 7-day-old seedling (B), in a 10-day-old seedling (C,D), in the development of the flower (E-H), in a young silique (I), and in the development of seeds (J). The arrowhead indicates the staining signal, and the encircled region in (D) is magnified. Bars = $1 \mathrm{~mm}$ (A,B,D), $2 \mathrm{~mm}$ (C,E-I), and $25 \mu \mathrm{m}$ (J). (K) Expression pattern of GAAP1 genes in 7-day-old seedlings assayed by q-PCR. Data are represented at the fold level relative to the level in the root. (L) Expression pattern of GAAP3 genes in young seedlings assayed by RT-PCR. GUS activity of GAAP3 during seed germination (M,N), in 4- and 14-day-old seedlings (O,P), in the whole inflorescence (Q), in the development of flower at stage 7-9 (R), stage 10-12 (S), and stage 13 (T).

of single mutant can be restored (data not shown).We also compared the primary root growth of each seedling on the medium containing TM. The root length of the GAAP3-overexpressing lines was less inhibited than that of the wild-type, whereas the primary root elongation of gaap3 and gaaplgaap3 double mutants was significantly impaired (Supplementary Figure S3). The inhibition of primary root growth of GAAP1-overexpressing line upon TM treatment was also reduced (data not shown). All these findings suggested GAAP1 and GAAP3 function in the resistance of plants to ER stress.

\section{GAAP1 and GAAP3 Functioned in Resistance to Cell Death Induced by ER Stress}

ER stress triggered by TM can induce PCD in rosette leaves and roots, and $0.30 \mu \mathrm{g} \mathrm{mL}^{-1} \mathrm{TM}$ is reportedly the sublethal dose for plants (Watanabe and Lam, 2008; Mishiba et al., 2013). Three-day-old Col seedlings were transferred into medium containing $0,0.15$, and $0.30 \mu \mathrm{g} \mathrm{mL}^{-1} \mathrm{TM}$. The pattern of root cell of Col injured over the time course upon TM treatment was first examined by FDA, PI, DAB, and trypan blue staining 


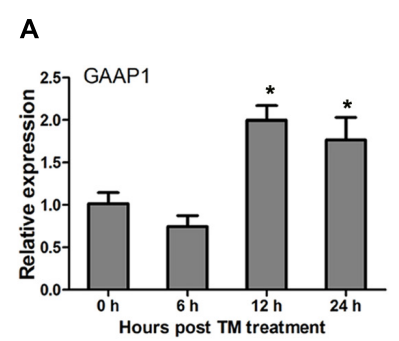

C

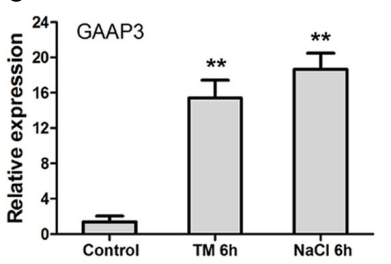

B

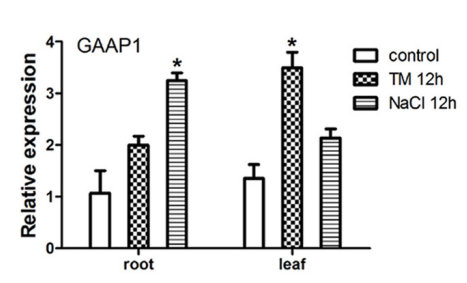

D

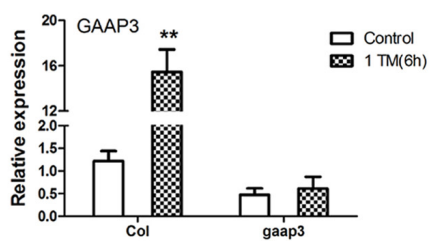

$\mathbf{E}$

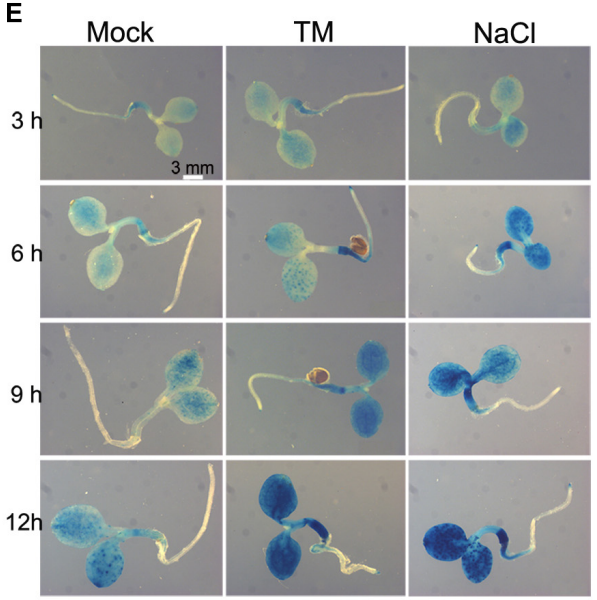

FIGURE 3 | Expression levels of GAAP1 and GAAP3 genes were induced by stress signals in Arabidopsis seedling. (A) Expression level of GAAP1 in 10-day-old plants in the presence of $0.5 \mu \mathrm{gL}^{-1} \mathrm{TM}$ at different hours, as assayed by q-PCR. (B) Expression level of GAAP1 in the root or leaf of 10-day-old plants in the absence or presence of $0.5 \mu \mathrm{g} \mathrm{mL}^{-1} \mathrm{TM}$ or $100 \mathrm{mmol} \mathrm{L}^{-1} \mathrm{NaCl}$ for $12 \mathrm{~h}$, as assayed by q-PCR. (C) Expression level of GAAP3 in 4-day-old plants in the presence of $0.5 \mu \mathrm{g} \mathrm{mL}{ }^{-1} \mathrm{TM}$ or $100 \mathrm{mmol} \mathrm{L}^{-1} \mathrm{NaCl}$ for $6 \mathrm{~h}$, as assayed by q-PCR. (D) Expression level of GAAP3 in 4-day-old seedlings of Col and gaap3 in the absence or presence of $1.0 \mu \mathrm{g} \mathrm{mL}-1$ TM for $6 \mathrm{~h}$, as assayed by qPCR. The relative gene expression was the level normalized to the control level in the wild-type (Col). (E) GUS staining for GAAP3::GUS in a 3-day-old seedling treated without or with $100 \mathrm{mmol} \mathrm{L}^{-1} \mathrm{NaCl}$ or $0.5 \mu \mathrm{g} \mathrm{mL}^{-1} \mathrm{TM}$ for 3-12 h. Data are represented as mean \pm SE for at least three biological replicates and the asterisk indicates significant differences between treatment and control samples $\left({ }^{*} p<0.05,{ }^{* *} p<0.01\right)$.

to determine cell viability, cell membrane permeability, ROS level, and cell death, respectively (Figure $\mathbf{5 A}$ ). At $36 \mathrm{~h}$, the accumulation of $\mathrm{H}_{2} \mathrm{O}_{2}$ stained by DAB occurred between meristem and elongation region, and this area was denoted as the transition zone (Figures 5A,C) (Baluska et al., 2010). Moreover, cells of stele in transition zone decayed as showed by trypan blue staining only with $0.30 \mu \mathrm{g} \mathrm{mL}^{-1} \mathrm{TM}$, and much fewer cells died with $0.15 \mu \mathrm{g} \mathrm{mL}{ }^{-1} \mathrm{TM}$. With further ER stress for $48 \mathrm{~h}$, ROS accumulation extended to root meristem and elongation region, and cell death was enhanced with $0.30 \mu \mathrm{g} \mathrm{mL}^{-1} \mathrm{TM}$. Cell death in the transition zone also appeared with $0.15 \mu \mathrm{g} \mathrm{mL} \mathrm{m}^{-1} \mathrm{TM}$ as showed by FDA, PI, and trypan blue staining (Figure 5A). DAPI is cell-membrane semipermeable, and fluorescence intensity significantly increases when they bind to nuclear DNA. With increased TM dose, root cells stained by DAPI also showed enhanced fluorescence signal in the transition zone (Figure 5B), which reflected increased cellmembrane permeability and condensed nuclei. Obviously, the cells in the transition zone were most sensitive to ER stress. With increased ER stress, ROS accumulation and cell death extended to root meristem and elongation region. The area of cell death increased in a TM-dose-dependent manner and over the time course.

To further determine whether GAAP1 and GAAP3 can inhibit PCD, we evaluated the root-cell viability of mutants and transgenic lines in response to TM for $48 \mathrm{~h}$. The cells of gaaplgaap3 double mutants showed the strongest signals, whereas 35S::GAAP1\#4 and GAAP3-OX showed the weakest signals of DAB, PI, and trypan blue staining (Figure 6 and Supplementary Figures S4, S5). These data suggested that GAAP1 and GAAP3 conferred increased tolerance to ER-stress-induced cell death.

\section{Effects of GAAP1 and/or GAAP3 Level on the Induction Pattern of UPR Genes Under Different ER Stress Conditions}

The hypersensitivity of gaaplgaap3 mutants and the resistance of GAAP1 or GAAP3 overexpressing plants to ER stress prompted us to determine whether GAAP1/GAAP3 protein directly or indirectly interfered with the UPR. We performed real-time PCR analysis to examine the expression of markers for UPR activation under three ER stress conditions. To determine whether UPR signaling was directly disturbed, we performed an assay under acute ER stress induced by high-dose TM $\left(5 \mu \mathrm{g} \mathrm{mL}^{-1}\right)$ for $4-6 \mathrm{~h}$. To examine the tunability of the UPR change pattern over the prolonged ER stress, we performed an assay under ER stress conditions caused by $0.5 \mu \mathrm{g} \mathrm{mL} \mathrm{m}^{-1} \mathrm{TM}$ for 4-36 h, which caused cell death (Figure 5). To examine the tunability of the UPR change pattern upon pulse-ER stress, we performed an assay during the recovery course after the short ER stress (treatment with $1.0 \mu \mathrm{g} \mathrm{mL}^{-1} \mathrm{TM}$ for $15 \mathrm{~min}$ ), which did not inflict much cell damage. Upon acute ER stress, the induction values of AtBIP3, AtBIP2, spliced AtbZIP60 (bZIP60s), AtPDIL, AtCRT1, and AtCNX1 and AtHSP70, which are common markers for UPR activation (Martinez and Chrispeels, 2003; Williams et al., 2010), in Col, gaap1-1, gaap1gaap3, and the GAAP1/GAAP3-overexpressing plants were similar, except for the lower upregulation of bZIP60s in GAAP1-overexpressing line (Supplementary Figures S6, S7). Additionally, the expression patterns of UPR genes in Col, gaap1-1, and gaap1gaap3 seedlings over the treatment course with $0.5 \mu \mathrm{g} \mathrm{mL}^{-1} \mathrm{TM}$ were compared (Figures 7A-G). Genes bZIP60s and NAC103 downstream the IRE1-dependent signaling pathway, genes AtPDIL, AtCNX1, and AtHSP70 downstream the bZIP28-dependent signaling pathway, 
A

TM 0
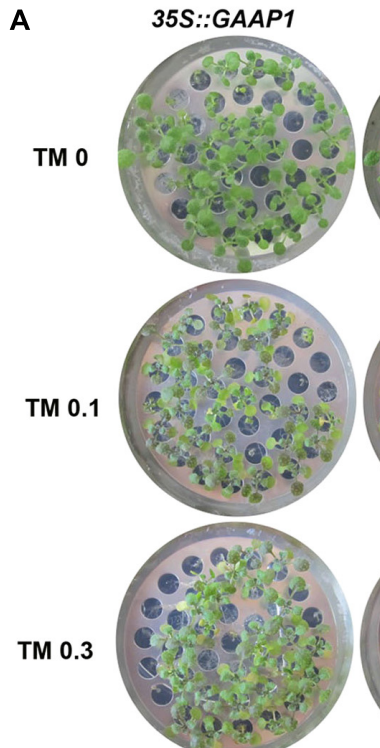

TM 0.5

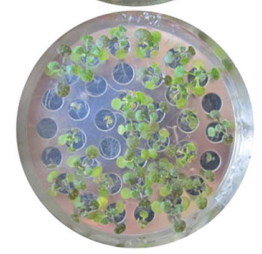

D

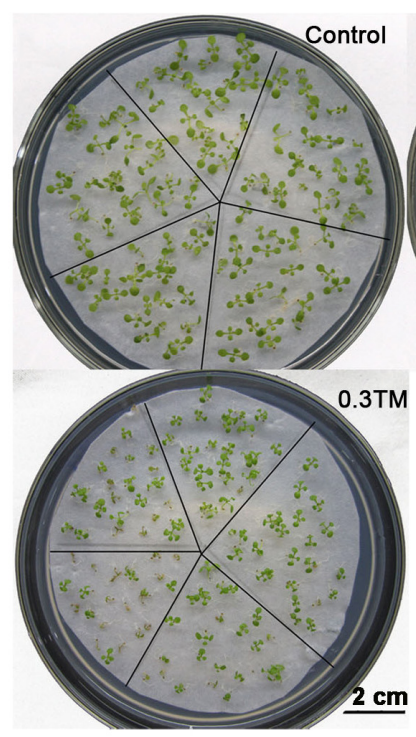

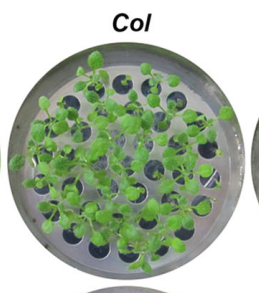
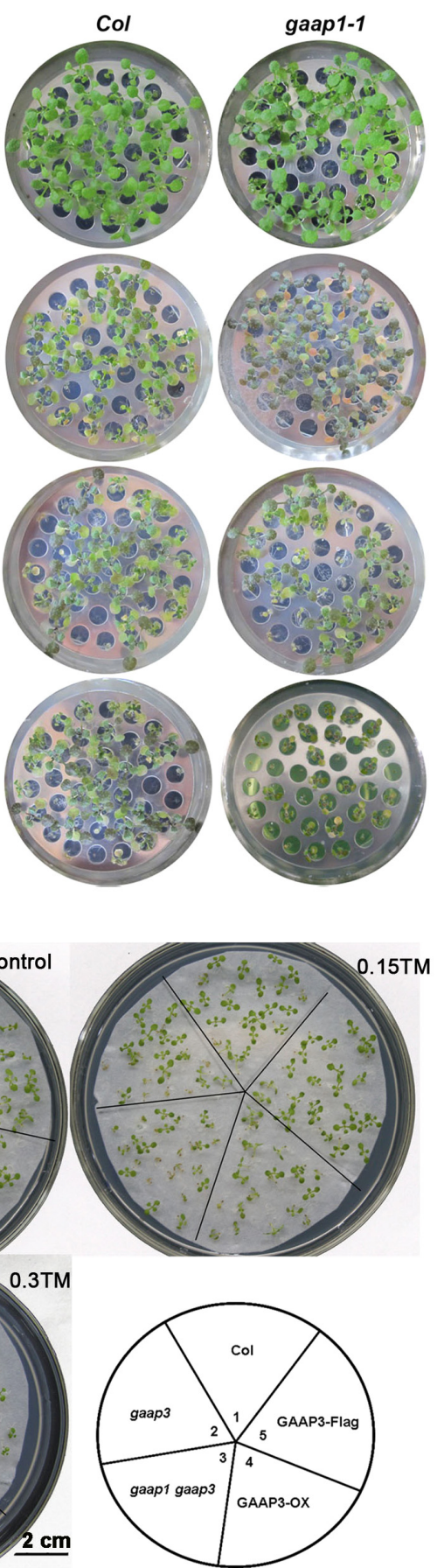

B

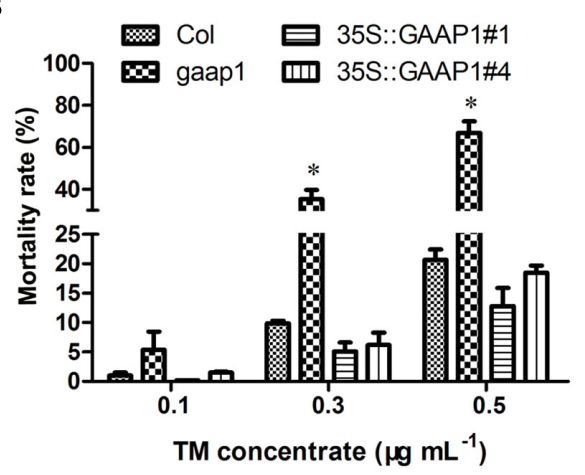

C

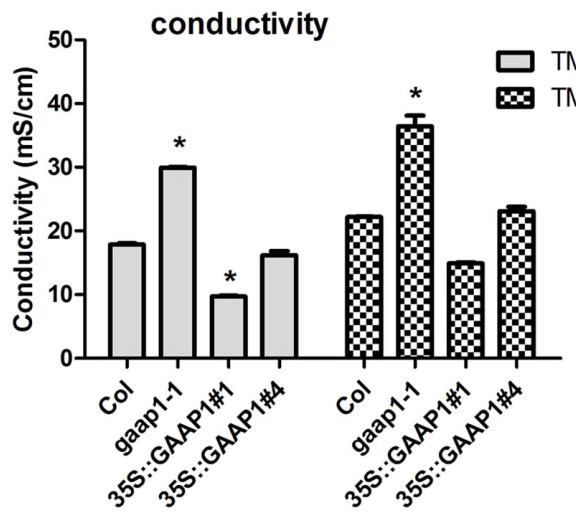

E

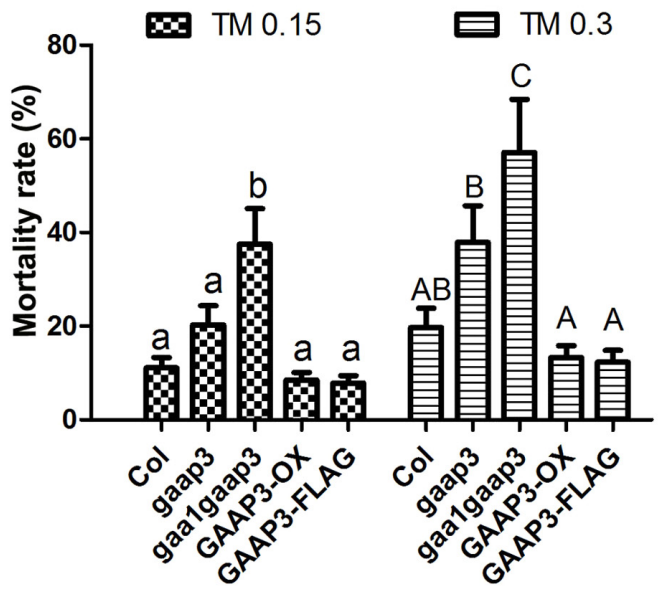

FIGURE 4 | Mutation of GAAP1 and/or GAAP3 enhanced plants sensitivity toward TM. (A-C) GAAP1 mutation-enhanced plant death induced by TM. (A) Growth of Col, 35S::GAAP1\#1 seedlings on 1/2 MS medium for 5 days, and then moved on $1 / 2 \mathrm{MS}$ medium supplied with different concentrations $(0-0.50 \mu \mathrm{g} \mathrm{mL}-1)$ of TM for 1 week. (B) Mortality rate of GAAP1-overexpressing transgenic plants, and Col and gaap1-1 treated with different concentrations of TM for 1 week. Error bars depict SE of six independent experiments. Error bars depict SD. Significant differences compared with Col plants at the same concentrations of TM, as indicated by asterisks $\left({ }^{*} p<0.05, \mathrm{n}>80\right)$. (C) Damage of GAAP1-overexpressing transgenic plants, Col and gaap1-1 treated with 0.3 and $0.50 \mu \mathrm{g} \mathrm{mL}{ }^{-1} \mathrm{TM}_{\text {for }} 1$ week. Shoots were collected from the samples obtained from the different sets of seedlings performed for (B) and then subjected to ion leakage measurements. Data are expressed as mean $\pm S D$. Significant differences compared with Col plants at the same concentrations of TM, as indicated by asterisks $\left({ }^{*} p<0.05, n=3\right)$. (D,E) GAAP3 single mutation or GAAP3 and GAAP1 double mutations reduced the resistance of plants to ER stress. Phenotypes (D) and mortality rates (E) of Col, gaap3, gaap1gaap3, GAAP3-OX, and GAAP3-FLAG, which grew on 1/2 MS medium without or with 0.15 and $0.30 \mu \mathrm{g} \mathrm{mL}^{-1}$ TM for 10 days. Data are expressed as mean \pm SE of five independent experiments. Different letters indicate significant differences between different plants with the same TM treatment subjected to $x^{2}$ test. 


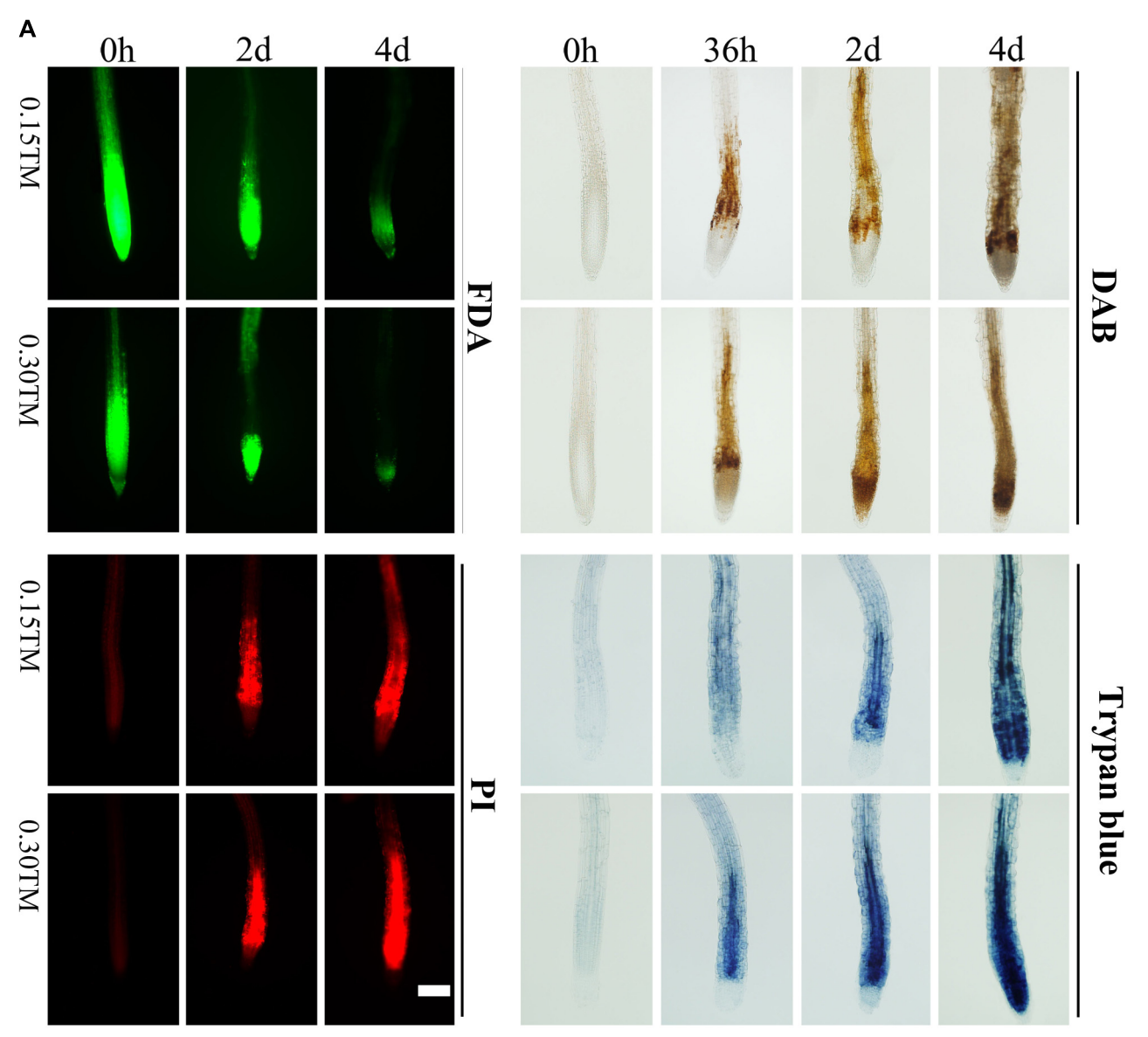

B

0TM

0.3TM 2d

1.0TM 2d
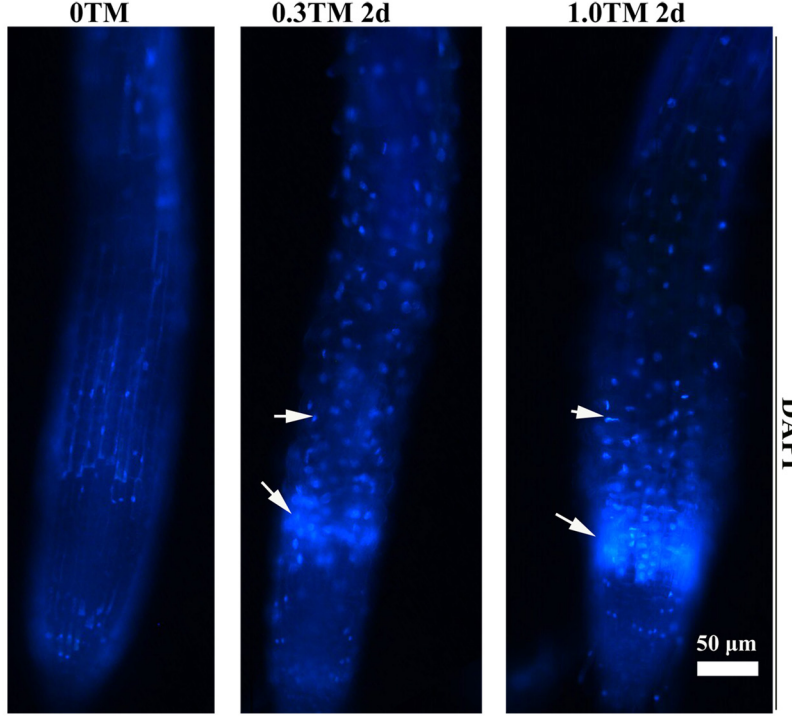

C

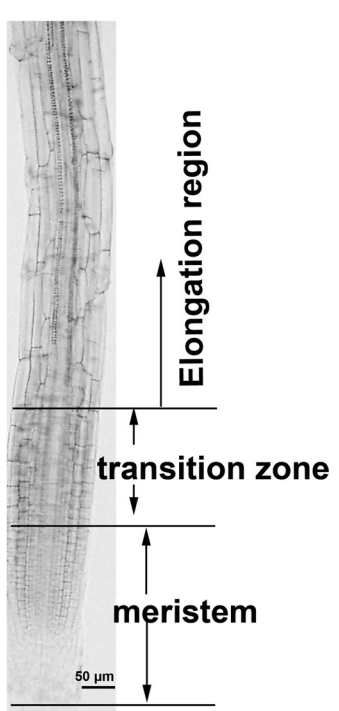

FIGURE 5 | Root cell death pattern under ER stress. (A) Time course analysis of root cell viability and ROS level upon TM treatment. The 3-day-old seedlings of vertically cultivated Col were transferred to new culture plate containing different concentrations of $\mathrm{TM}\left(0,0.15\right.$, and $\left.0.30 \mu \mathrm{gL}^{-1}\right)$ and root cells were stained by FDA, PI, DAB, and Trypan blue after $0 \mathrm{~h}, 36 \mathrm{~h}, 2$ days, and 4 days, respectively. The staining level of root on the medium without TM did not change over the time course and were same as those at " $\mathrm{O}$ ". Bar $=100 \mu \mathrm{m}$. (B) Root cell death pattern stained by DAPI under ER stress. The 3-day-old seedlings of Col were transferred to a new liquid culture medium containing different concentrations of TM $\left(0,0.3\right.$, and $\left.1.0 \mu \mathrm{g} \mathrm{mL}^{-1}\right)$ for an additional 2 days and root cells were stained by DAPI. (C) Different regions of the primary root. Bar $=50 \mu \mathrm{m}$. 


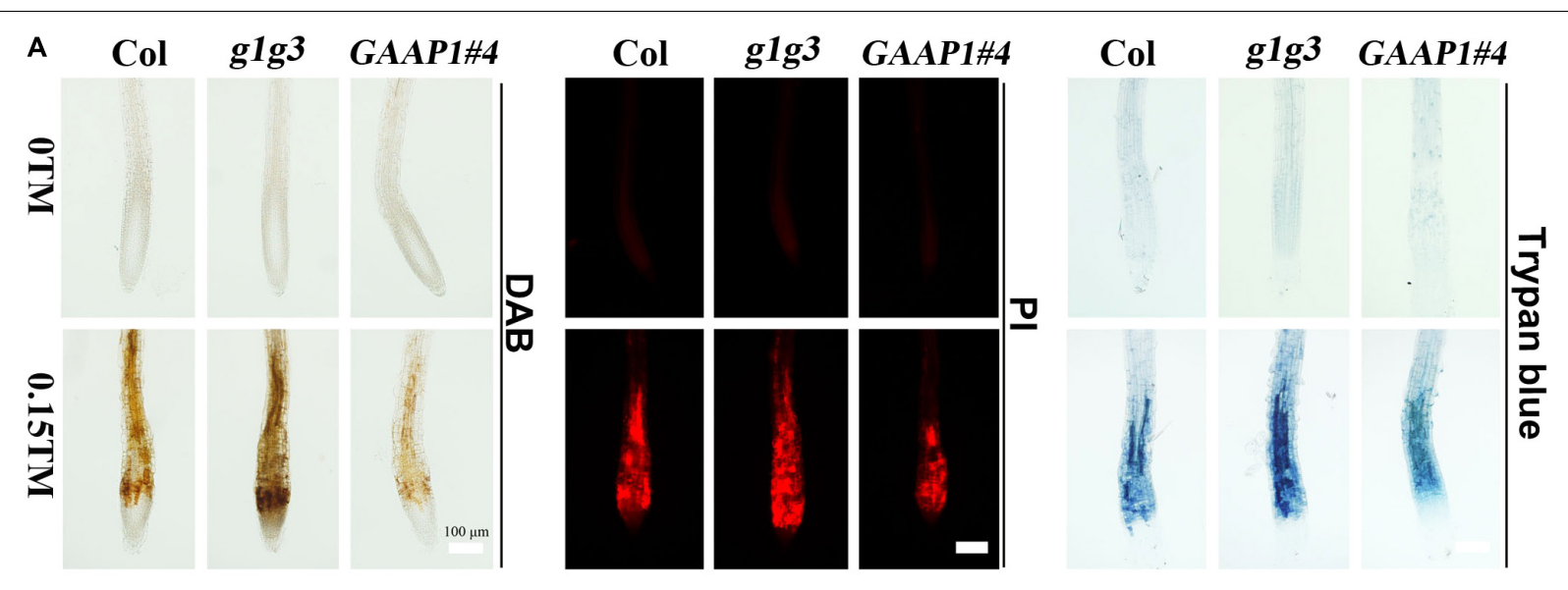

B

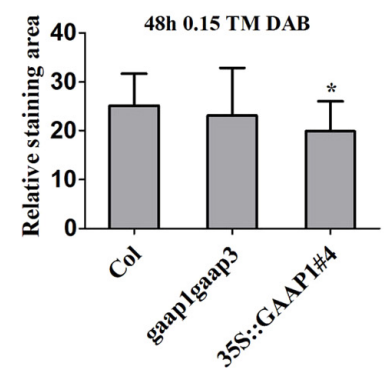

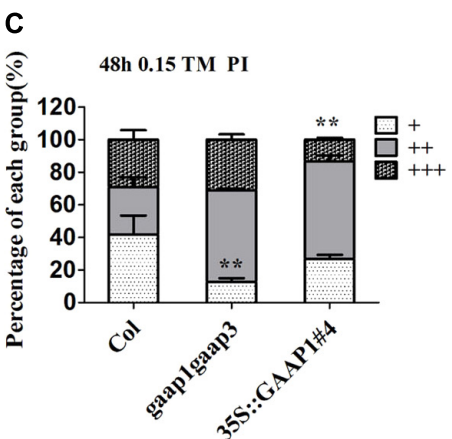

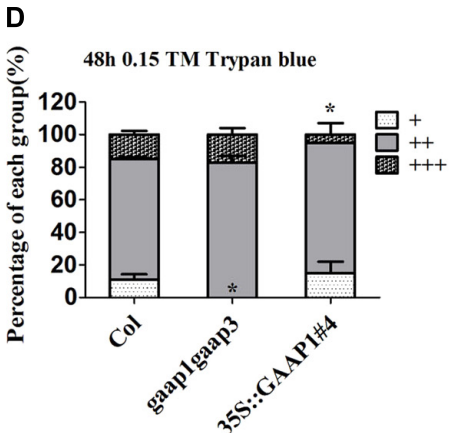

FIGURE 6 | GAAP1/GAAP3 inhibited the cell death induced by ER stress. (A) The 3-day-old seedlings that were vertically cultured were transferred to a new culture plate containing different concentrations of TM. Root cells of Col, gaap1gaap3 (g1g3), and 35S::GAAP1\#4 treated without or with $0.15 \mu \mathrm{g} \mathrm{mL}-1$ TM for $48 \mathrm{~h}$ were stained by DAB, PI, and trypan-blue. Bar = $100 \mu \mathrm{m}$. (B-D) The $\mathrm{H}_{2} \mathrm{O}_{2}$ level (B) and cell death severity (C,D) were analyzed by quantifying the staining degree. DAB staining area of the signal intensity more than a certain threshold was determined by Image J software. PI and trypan blue staining intensity were classified in three levels, namely, faint, medium, and strong, and depicted as "+", "++", and "+++", respectively, according to Supplementary Figure S4. The percentage of each group was calculated. Error bars represent standard deviation. Significant differences compared with Col plants were indicated by asterisks (student test, * $p<0.05$, $n \geqq 20)$.

and $A t B I P 3$, which belongs to both pathways, were selected (Liu et al., 2007; Mishiba et al., 2013). The data showed that the IRE1 pathway genes peaked and then declined with persistent ER stress, and the bZIP28 pathway genes remained upregulated over 36 h. GAAP1 and GAAP3 mutations enhanced bZIP60s, NAC103, and $A t C N X 1$ upregulation at $4 \mathrm{~h}$ following TM treatment. However, the expression levels and patterns of bZIP60s and NAC103 downstream the IRE1-dependent signaling pathway were severely affected by the gaaplgaap 3 double mutant, thus peaking earlier and higher than Col following ER stress. The transcript levels of bZIP60s and NAC103 displayed a decline with prolonged ER stress at around $36 \mathrm{~h}$ in Col and gaap1-1 seedlings, and around $12 \mathrm{~h}$ in the gaap1gaap 3 double mutant (Figures 7C,D). Only the expression levels were different, but not the patterns of the bZIP28 pathway genes, in the mutants over the time course (Figures $\mathbf{7 B}, \mathbf{E}-\mathbf{G}$ ). The upregulation of most UPR genes tested were reduced in the single gaap1-1 and double gaaplgaap 3 mutants over $12 \mathrm{~h}$ following TM treatment. These data suggested that GAAP1 and GAAP3 play antagonistic roles in UPR gene induction at the beginning of mild ER stress. However, with persistent ER stress, the UPR gene induction level was lower in the gaap1 single and gaap1gaap 3 double mutants than those in the wild-type. A previous report showed that $\mathrm{TM}$ at $0.5 \mu \mathrm{g} \mathrm{mL}^{-1}$ for 3 days is lethal for Arabidopsis seedlings (Watanabe and Lam, 2008). The above data showed that root cell death can be detected with $0.3 \mu \mathrm{g} \mathrm{mL}{ }^{-1} \mathrm{TM}$ for $36 \mathrm{~h}$, and the cell death induced by TM was enhanced in gaap1gaap3 (Figures 5, 6). Accordingly, the attenuated induction of UPR gene mRNA in gaap1 single and gaap1gaap3 double mutants upon chronic ER stress induced by $0.5 \mu \mathrm{g} \mathrm{mL} L^{-1}$ TM (Figures 7A-G) may be caused by the cell damage in mutants

To avoid cell damage caused by high-dose or chronic ER stress, we evaluated the expression pattern of UPR genes in gaap1gaap3 and GAAP1-overexpressing seedlings during the recovery course from short-term ER stress. Figures $7 \mathbf{H}-\mathbf{K}$ show similar upregulation levels of representative UPR genes of both signaling pathways, including AtBIP3, bZIP60s, and AtCNX1, in all plant lines upon recovery for 6-48 h. By $72 \mathrm{~h}$, the transcripts levels of AtBip 3 and bZIP60s decreased and both genes were nearly reduced to the basal level in the two GAAP1-overexpressing lines. NAC103, the direct target 


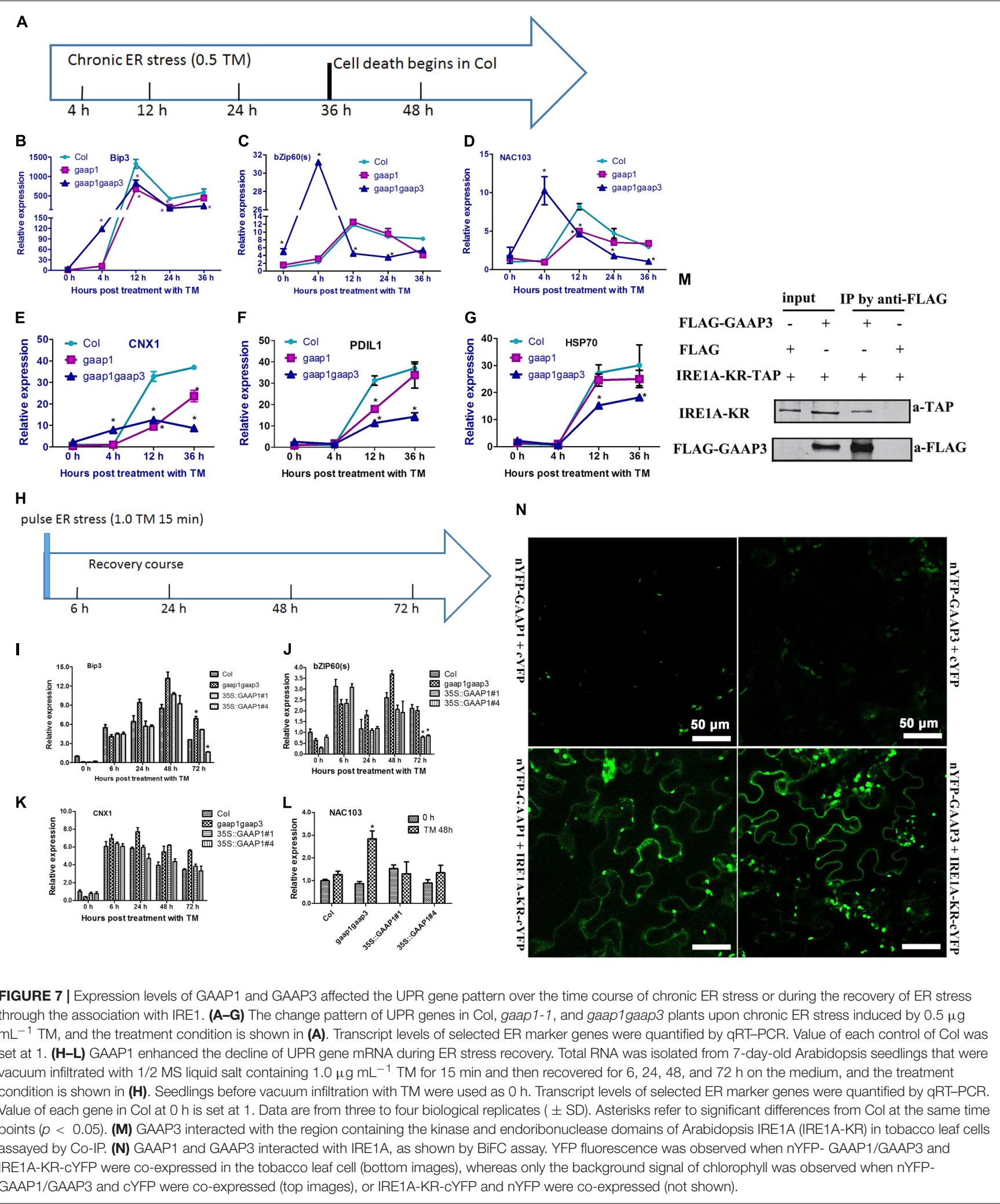

of bZIP60s, showed the highest level in gaap1gaap3 mutant $48 \mathrm{~h}$ post recovery (Figure 7L). The levels of bZIP28 pathway marker gene AtCNX1 in all plant lines were not different
(Figures 7G-J). These data suggested that alterations in GAAP1/GAAP3 expression levels may interfere with the UPR at the transcriptional level, and that GAAP1 and GAAP3 enhance 
the attenuation of the IRE1 signaling pathway activation during recovery from the ER stress fluctuation.

\section{GAAP1/GAAP3 Interacted With IRE1 in Vivo}

The above results of the molecular pattern assay over the time course of ER stress suggest that the expression of GAAP1/GAAP3 negatively modulates the splicing activity of IRE1 for bZIP60. To test if GAAP1/GAAP3 regulates IRE1 directly, we searched for the interaction between GAAP3 and IRE1A. The region containing the kinase and endoribonuclease domains of Arabidopsis IRE1A fused with the N-terminal TAP tag was generated based on the result that BI-1 interaction requires the cytosolic C-terminal region of IRE1 $\alpha$ encoding the kinase and endoribonuclease domains in the human cell (Lisbona et al., 2009). Co-IP experiments using lysates from tobacco leaf cells that were co-transformed with IRE1A-KR-TAP and FLAG-GAAP3 showed an association between both proteins (Figure $7 \mathrm{M}$ ). For the $\mathrm{BiFC}$ assay, we fused the $\mathrm{N}$ - terminal halves of YFP to the N termini of GAAP1 and GAAP3, and the C-terminal halves of YFP to the C-termini of IRE1A and IRE1B, which encode the kinase and endoribonuclease domains, respectively. Strong YFP fluorescence was observed when the nYFP-GAAP1/GAAP3 and IRE1A-KR-cYFP or IRE1B-KR-cYFP were coexpressed in the tobacco leaf cell (Figure $7 \mathrm{~N}$ and Supplementary Figure S8), suggesting that GAAP1/GAAP3 interacted with IRE1A or IRE1B.

\section{Overexpressing GAAP1 and/or GAAP3 Were Conducive to the Growth of Plants After the ER Stress}

The results that GAAP1 and GAAP3 enhanced the attenuation of the IRE1 signaling pathway during the recovery from ER stress prompted us to further examine whether they are conducive to growth under such condition. The 4-day-old seedlings were infiltrated with $0,0.15$, and $1.00 \mu \mathrm{g} \mathrm{mL}^{-1} \mathrm{TM}$ for $6 \mathrm{~h}$ and then transferred to the normal solid medium. No obvious etiolation or growth damage in all tested lines was observed during the culture. Moreover, the decreased fresh seedling weight of GAAP1 or GAAP3-overexpressing lines was significantly lower than that of the wild-type, whereas the inhibition rate of the gaaplgaap3 seedling was higher (Figures 8A-D and Supplementary Figure S9). These data were consistent with the hypothesis that GAAP1 and GAAP3 promoted the downregulation of the cell protective response and favored the energy redistribution for growth after mild ER stress was relieved.

\section{DISCUSSION}

\section{GAAP1 and GAAP3 Inhibit Cell Death Under ER Stress}

GAAPs are broadly conserved cytoprotective proteins and they are localized in the membranes of the ER and the Golgi apparatus (Henke et al., 2011). Moreover, the human hGAAP inhibits apoptosis triggered by intrinsic and extrinsic stimuli
(Gubser et al., 2007). GAAP1 and GAAP3, the homologs of h-GAAP in Arabidopsis, were localized on membranes, including the ER membrane, according to the protein secondary structure prediction and cellular localization assay (Figure 1). Consistent with this, GAAP1 and GAAP3 interacted with IRE1 (Figures 7M,N and Supplementary Figure S8), which is a UPR sensor located on the ER membrane. ER is the best-known organelle, aside from mitochondrion, for regulating the PCD in plant cells (Chen et al., 2010). Additionally, Arabidopsis GAAP1 and GAAP3 genes expression were enhanced, especially the GAAP3 gene, under ER or salt stress conditions (Figure 3), which suggested that GAAP1 and GAAP3 are physiologically associated with cell death control and/or stress management. Moreover, TM disturbs root development in a dose-dependent manner, concomitantly with the loss of cell viability and induction of PCD phenotypes (Watanabe and Lam, 2008; Nagashima et al., 2011). In this study, the cells of the transition region of the root were the most sensitive to ER stress, and the scope and amount of cell death expanded and increased around this region with the severity of ER stress (Figure 5). Consistent with this, cells in the transition zone undergo notable cell wall alterations and display unique cytological and metabolic properties that allow them to sense and respond to diverse environmental factors and endogenous cues (Verbelen et al., 2006). The hypersensitivity of GAAP1 and GAAP3 single or double mutants and the resistance of plants that overexpressed GAAP1 or GAAP3 to ER stress (Figures 4, 6 and Supplementary Figures S3, S4) suggested that GAAP1 and GAAP3 play redundant roles in maintaining plant growth and survival under ER stress, at least partly by attenuating cell death. It has been shown that ER stress can induce ROS production and also oxidative stress can induce ER stress (Ozgur et al., 2014, 2015). ROS can be stress response signaling and also leads to cell death depending on its dose. GAAP1 and GAAP3 predominately located in the plasma membrane and affected ROS level upon ER stress (Figures 1, 6). Whether GAAP1 and GAAP3 resistance to cell death induced by ER stress is mediated by the influence of ROS production needs further research.

\section{GAAP1/GAAP3 Inhibited IRE1 Pathway Under Mild ER Stress}

IRE1A/B and bZIP28 are the two main pathways of UPR for the adaption in plants (Liu et al., 2007; Mishiba et al., 2013). Moreover, unmitigated ER stress induces PCD in animals and plants (Lisbona et al., 2009; Yang et al., 2014). However, knowledge regarding the different activities of UPR sensors between adaption and cell death stations in plant is limited. And little is also known how the UPR activation is downregulated to ensure plant growth when the stress is mitigated. Recently, Arabidopsis BI-1 has been reported to attenuate the pro-survival function of bZIP28 but not temper the ribonuclease activity of IRE1 in recovery roles from temporary ER stress (Ruberti et al., 2018). To define the possible regulation of both pathways by GAAP1/GAAP3, we determined the level and pattern of the representative marker genes in the gaaplgaap3 mutant over the time course of persistent ER stress. As expected, the protective marker genes of both UPR pathways were significantly upregulated upon $0.5 \mu \mathrm{g} \mathrm{mL}^{-1} \mathrm{TM}$ treatment in all 
A

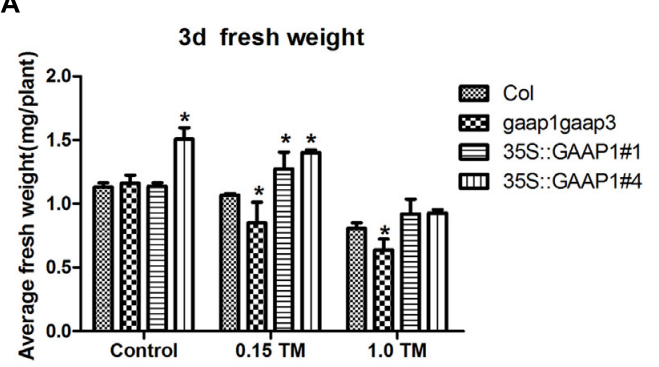

C

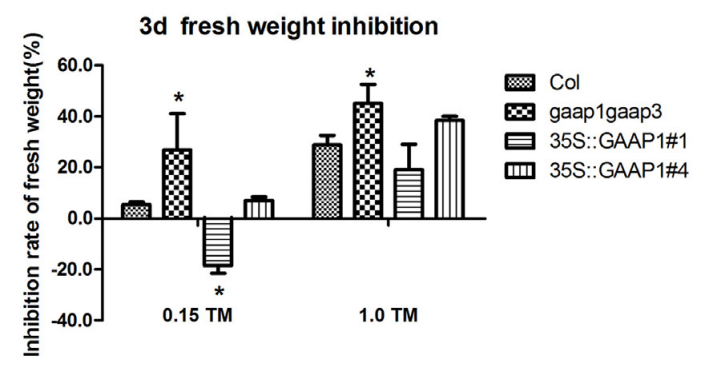

B

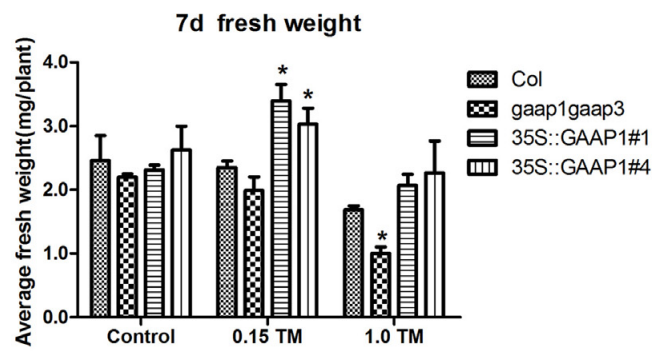

D

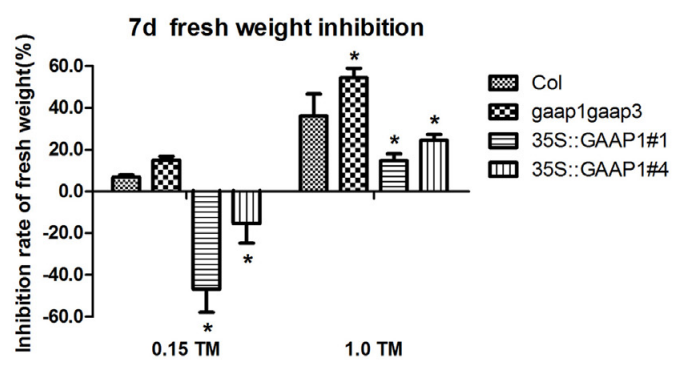

E
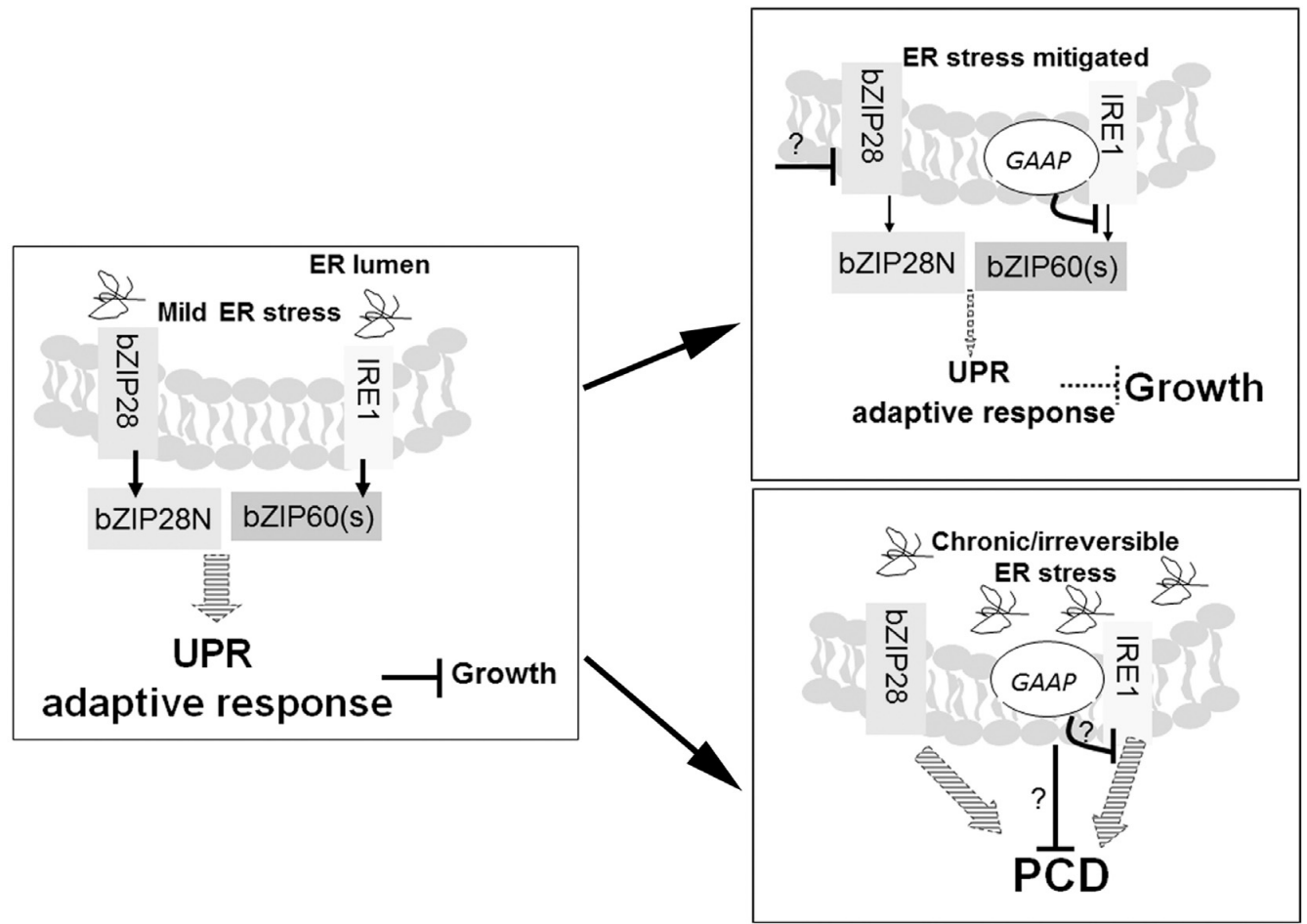

FIGURE 8 | GAAP1/GAAP3 promoted growth recovery after mild ER stress was relieved and the working model of the function of GAAP1/GAAP3.(A-D) The 4-day-old seedlings that were infiltrated with $1 / 2 \mathrm{MS}$ liquid salt containing $0,0.15$, and $1.0 \mu \mathrm{g} \mathrm{mL}^{-1} \mathrm{TM}$ for $6 \mathrm{~h}$ were transferred to the $1 / 2 \mathrm{MS}$ solid medium. Fresh weight of seedlings (A,B) and inhibition rates (C,D) were determined after recovery for 3 and 7 days. Data are from three biological replicates ( \pm SE) and at least 30 samples for each plant line were used for each treatment. Asterisks refer to significant differences from Col at the same time points and same conditions ( $t$-test; $p<0.05$ ). (E) Working model of the dual role of GAAP1/GAAP3 in the regulation of UPR and PCD. In cells undergoing mild ER stress, rapid adaptive responses were initiated through UPR signaling mediated by bZIP28 and IRE1 at the cost of growth inhibition. Usually the weak inhibition role of the low level of GAAP1/GAAP3 in vivo under such condition makes cells increases the competence for UPR signaling. The artificial ectopic expression GAAP1/GAAP3 will postpone the activated UPR signaling. GAAP1/GAAP3 level will be upregulated upon ER stress and then down-regulated upon UPR signaling by inhibiting IRE1 activity to soon recover plant growth when the ER stress is mitigated. GAAP1/GAAP3 negatively controls IRE1 activity via direct association. If the ER stress is persistent or severe, PCD will be induced. GAAP1/GAAP3 might regulate the downstream PCD machinery or negatively control IRE1, thereby inhibiting cell death initiated by diverse intrinsic death stimuli, including irreversible ER stress. 
plant lines for several hours. Moreover, gaap1gaap3 displayed a more rapid and more pronounced upregulation of UPR genes mRNA at the beginning of treatment, but lower induction level of UPR genes as ER stress proceeded, compared with Col. Additionally, the upregulation of the IRE1 pathway genes (BIP3, spliced bZIP60, and NAC103) declined with prolonged ER stress in all plants. In human cells, the activation IRE1 signaling pathway initially declines after prolonged ER stress, accompanied by cell death. Furthermore, cell survival can be enhanced if IRE1 activity is artificially sustained (Lin et al., 2007). In fact, cell death was observed around $36 \mathrm{~h}$ post treatment with $0.5 \mu \mathrm{g} \mathrm{mL}^{-1} \mathrm{TM}$ (Watanabe and Lam, 2008) (Figure 5), the dose used to induce chronic ER stress. Cells in gaap1gaap3 seedlings exhibited pronounced death upon chronic ER stress (Figure 6 and Supplementary Figure S5). Moreover, the induction of IRE1 pathway genes peaked and weakened rapidly in the gaap1 gaap3 plants (Figures 7A-G). A certain relationship may exist between the amplitude modulation of IRE1 activity and cell death. IRE1 mutation in plant or human cell enhances programmed cell death (Mishiba et al., 2013). These data suggest that plant and mammalian cells share the conserved regulation mechanism, which is the declining of the IRE1 adaptive pathway accompanied with the initiation of cell death secondary to persistent ER stress. Enhanced activation of the IRE1 pathway only upon the early stage of mild ER stress in gaaplgaap3 seedlings (Figures 7A-D) and no significantly different induction levels in most UPR genes except for bZIP60(S) were observed when plants were treated with high doses of TM, namely, $5 \mu \mathrm{g} \mathrm{mL} \mathrm{m}^{-1}$, for a few hours (Supplementary Figures S6, S7), indicating that GAAP1/GAAP3 is a modulator of UPR and might function as the inhibitor of IRE1 adaptive pathway.

\section{GAAP1/GAAP3 Promoted the Growth Recovery After the Mild ER Stress Was Relieved by Weakening the UPR Activity}

To further validate the possible inhibitory effects of GAAP1/GAAP3 on UPR, we monitored UPR genes in Col-, gaap1gaap3-, and GAAP1-overexpressing lines during the recovery period after the pulse TM treatment. Under such experimental conditions, no obvious plant death and etiolation were observed, and a similar upregulation level of representative UPR genes of both signaling pathways in all plant lines recovery for $6 \mathrm{~h}$ till $48 \mathrm{~h}$. At $72 \mathrm{~h}$ post-recovery, the transcripts levels of AtBIP3 and bZIP60s, which are IRE1A/B pathway genes decreased. Moreover, the IRE1A/B pathway genes nearly decreased the basal level in the GAAP1-overexpressing lines, whereas the highest level of NAC103 gene was retained in the gaap1gaap 3 mutant at $48 \mathrm{~h}$. The bZIP28 pathway-marker gene AtCNX1 levels were not different in all plant lines at each time point (Figures $\mathbf{7 H}-\mathbf{K}$ ). These data showed that GAAP1 and/or GAAP3 might specifically enhance the attenuation of the IRE1 signaling pathway activation during the recovery from ER stress fluctuation. Moreover, engagement of the IRE1 pathway confers protection against ER stress. The inhibitory effect on UPR was evident when confronted with low doses of ER stressors, which resembled in vivo normal conditions, wherein plant cells are equipped to cope with injury (adaptive conditions). In agreement with these findings, we observed low levels of GAAP3 and GAAP1 and their expression level increased upon ER stress (Figures 2, 3). Similar functions of the BI-1 upon inactivation of IRE1 $\alpha$ signaling through interacting with each other in human cells have been reported (Lisbona et al., 2009). Additionally, GAAP1 and GAAP3 interacted with IRE1A or IRE1B in plants (Figures 7M,N and Supplementary Figure S8). The attenuation of the cytoprotective action of IRE1 signaling by GAAP1 and/or GAAP3 when the ER stress is relieved should be advantageous for normal growth recovery with sufficient energy. In agreement with such hypothesis, the improved biomass production in GAAP1- or GAAP3-overexpressing lines was determined after short-term ER stress (Figures 8A-D and Supplementary Figure S9). Thus, the results indicated that GAAP1/GAAP3 displays a dual function in fine tuning UPR signaling and downstream PCD (model in Figure 8E). Considering the low level of both genes in normal growth conditions and their upregulated expression levels secondary to stress signals, the primary functions of GAAP1/GAAP3 might be to weaken the UPR activity and make cells recover from protection to growth upon relief of ER stress. Along with the recent finding that Arabidopsis BI-1 attenuates the pro-survival function of bZIP28 in ER stress resolution, this finding indicates that BI-1-relevant members might be involved in fine tuning the activity of UPR receptors in plants. Therefore, the mechanism of the anti-PCD activity of GAAP1 and/or GAAP3 upon ER stress needs further research.

\section{ACCESSION NUMBERS}

The Arabidopsis Genome Initiative accession numbers for the proteins referred to in the paper are At4G14730 (GAAP1), At4G02690 (GAAP3), At3G10800 (bZIP28), At1g49240 (ACTIN8), At1G09080 (BIP3), At1G42990 (bZIP60), At5G24360 (IRE1B), At4G16660 (HSP70), At4g24190 (SHD), At5g61790 (CNX1), At5G64060 (NAC103), and At2G17520 (IRE1A).

\section{AUTHOR CONTRIBUTIONS}

KG and WF performed the assay about plant sensitivity to ER stress. WeiW performed the protein interaction and cellular localization assay. ZW, MZ, and XT conducted the UPR assay. WenW, XY, and XS performed the expression of GAAP1 and GAAP3. YS and WZ supervised the physiological experiments and participated in interpreting the morpho-physiological data. XL designed the experiments, supervised the study, analyzed the data, and wrote the paper.

\section{FUNDING}

This work was supported by the National Natural Science Foundation of China (Grant No. 31670271) and the 
Shanghai Natural Science Program (Grant No. 15ZR141 0900).

\section{ACKNOWLEDGMENTS}

We thank Dr. Lin Xu (Shanghai Institute of Plant Physiology and Ecology, Chinese Academy of Sciences) and Dr. Hong-Li Lian (Shanghai Jiao-Tong University)

\section{REFERENCES}

Baluska, F., Mancuso, S., Volkmann, D., and Barlow, P. W. (2010). Root apex transition zone: a signalling-response nexus in the root. Trends Plant Sci. 15, 402-408. doi: 10.1016/j.tplants.2010.04.007

Bolte, S., Talbot, C., Boutte, Y., Catrice, O., Read, N. D., and Satiat-Jeunemaitre, B. (2004). FM-dyes as experimental probes for dissecting vesicle trafficking in living plant cells. J. Microsc. 214, 159-173. doi: 10.1111/j.0022-2720.2004. 01348.x

Brewer, J. W. (2014). Regulatory crosstalk within the mammalian unfolded protein response. Cell. Mol. Life. Sci. 71, 1067-1079. doi: 10.1007/s00018-013-1490-2

Carrara, G., Parsons, M., Saraiva, N., and Smith, G. L. (2017). Golgi anti-apoptotic protein: a tale of camels, calcium, channels and cancer. Open Biol. 7:170045. doi: 10.1098/rsob.170045

Carrara, G., Saraiva, N., Gubser, C., Johnson, B. F., and Smith, G. L. (2012). Six-transmembrane topology for Golgi anti-apoptotic protein (GAAP) and Bax inhibitor 1 (BI-1) provides model for the transmembrane Bax inhibitor-containing motif (TMBIM) family. J. Biol. Chem. 287, 15896-15905. doi: 10.1074/jbc.M111.336149

Chen, Y., Lewis, W., Diwan, A., Cheng, E. H., Matkovich, S. J., and Dorn, G. W. (2010). Dual autonomous mitochondrial cell death pathways are activated by Nix/BNip3L and induce cardiomyopathy. Proc. Natl. Acad. Sci. U.S.A. 107, 9035-9042. doi: 10.1073/pnas.0914013107

Dai, F., Lee, H., Zhang, Y., Zhuang, L., Yao, H., Xi, Y., et al. (2016). BAP1 inhibits the ER stress gene regulatory network and modulates metabolic stress response. Proc. Natl. Acad. Sci. U.S.A. 114, 3192-3197. doi: 10.1073/pnas.1619588114

Deng, Y., Humbert, S., Liu, J. X., Srivastava, R., Rothstein, S. J., and Howell, S. H. (2011). Heat induces the splicing by IRE1 of a mRNA encoding a transcription factor involved in the unfolded protein response in Arabidopsis. Proc. Natl. Acad. Sci. U.S.A. 108, 7247-7252. doi: 10.1073/pnas.1102117108

Dhanasekaran, D. N., and Reddy, E. P. (2008). JNK signaling in apoptosis. Oncogene 27, 6245-6251. doi: 10.1038/onc.2008.301

Duan, Y., Zhang, W., Li, B., Wang, Y., Li, K., Sodmergen, G., et al. (2010). An endoplasmic reticulum response pathway mediates programmed cell death of root tip induced by water stress in Arabidopsis. New Phytol. 186, 681-695. doi: 10.1111/j.1469-8137.2010.03207.x

Flusberg, D. A., and Sorger, P. K. (2015). Surviving apoptosis: life-death signaling in single cells. Trends Cell Biol. 25, 446-458. doi: 10.1016/j.tcb.2015.03.003

Gubser, C., Bergamaschi, D., Hollinshead, M., Lu, X., van Kuppeveld, F. J., and Smith, G. L. (2007). A new inhibitor of apoptosis from vaccinia virus and eukaryotes. PLoS Pathog. 3:e17. doi: 10.1371/journal.ppat.0030017

Haze, K., Yoshida, H., Yanagi, H., Yura, T., and Mori, K. (1999). Mammalian transcription factor ATF6 is synthesized as a transmembrane protein and activated by proteolysis in response to endoplasmic reticulum stress. Mol. Biol. Cell 10, 3787-3799. doi: 10.1091/mbc.10.11.3787

Henke, N., Lisak, D. A., Schneider, L., Habicht, J., Pergande, M., and Methner, A. (2011). The ancient cell death suppressor BAX inhibitor-1. Cell Calcium 50, 251-260. doi: 10.1016/j.ceca.2011.05.005

Hetz, C. (2012). The unfolded protein response: controlling cell fate decisions under ER stress and beyond. Nat. Rev. 13, 89-102. doi: 10.1038/nrm3270

Hetz, C., and Glimcher, L. H. (2009). Fine-tuning of the unfolded protein response: assembling the IRE1alpha interactome. Mol. Cell 35, 551-561. doi: 10.1016/j. molcel.2009.08.021

Hu, L., Smith, T. F., and Goldberger, G. (2009). LFG: a candidate apoptosis regulatory gene family. Apoptosis 14, 1255-1265. doi: 10.1007/s10495-0090402-2 for kindly supplying the TAP-fusion vector and $\mathrm{pHB}$ vector.

\section{SUPPLEMENTARY MATERIAL}

The Supplementary Material for this article can be found online at: https://www.frontiersin.org/articles/10.3389/fpls.2018.00348/ full\#supplementary-material

Humbert, S., Zhong, S., Deng, Y., Howell, S. H., and Rothstein, S. J. (2012). Alteration of the bZIP60/IRE1 pathway affects plant response to ER stress in Arabidopsis thaliana. PLoS One 7:e39023. doi: 10.1371/journal.pone.0039023

Iwata, Y., Fedoroff, N. V., and Koizumi, N. (2008). Arabidopsis bZIP60 is a proteolysis-activated transcription factor involved in the endoplasmic reticulum stress response. Plant Cell 20, 3107-3121. doi: 10.1105/tpc.108. 061002

Iwata, Y., and Koizumi, N. (2012). Plant transducers of the endoplasmic reticulum unfolded protein response. Trends Plant Sci. 17, 720-727. doi: 10.1016/j.tplants. 2012.06.014

Lam, E. (2004). Controlled cell death, plant survival and development. Nat. Rev. 5, 305-315. doi: 10.1038/nrm1358

Leite, M., Quinta-Costa, M., Leite, P. S., and Guimaraes, J. E. (1999). Critical evaluation of techniques to detect and measure cell death-study in a model of UV radiation of the leukaemic cell line HL60. Anal. Cell. Pathol. 19, 139-151. doi: 10.1155/1999/176515

Li, G., Zhang, J., Li, J., Yang, Z., Huang, H., and Xu, L. (2012). Imitation Switch chromatin remodeling factors and their interacting RINGLET proteins act together in controlling the plant vegetative phase in Arabidopsis. Plant J. 72, 261-270. doi: 10.1111/j.1365-313X.2012.05074.x

Li, X. F., Jia, L. Y., Xu, J., Deng, X. J., Wang, Y., Zhang, W., et al. (2013). FT-like NFT1 gene may play a role in flower transition induced by heat accumulation in Narcissus tazetta var. chinensis. Plant Cell Physiol. 54, 270-281. doi: 10.1093/ $\mathrm{pcp} / \mathrm{pcs} 181$

Li, X. F., Li, Y. J., An, Y. H., Xiong, L. J., Shao, X. H., Wang, Y., et al. (2009). AKINbetal is involved in the regulation of nitrogen metabolism and sugar signaling in Arabidopsis. J. Integr. Plant Biol. 51, 513-520. doi: 10.1111/j.17447909.2009.00811.x

Lin, J. H., Li, H., Yasumura, D., Cohen, H. R., Zhang, C., Panning, B., et al. (2007). IRE1 signaling affects cell fate during the unfolded protein response. Science 318, 944-949. doi: 10.1126/science.1146361

Lin, J. H., Li, H., Zhang, Y., Ron, D., and Walter, P. (2009). Divergent effects of PERK and IRE1 signaling on cell viability. PLoS One 4:e4170. doi: 10.1371/ journal.pone.0004170

Lisbona, F., Rojas-Rivera, D., Thielen, P., Zamorano, S., Todd, D., Martinon, F., et al. (2009). BAX inhibitor-1 is a negative regulator of the ER stress sensor IRE1alpha. Mol. Cell 33, 679-691. doi: 10.1016/j.molcel.2009.02.017

Liu, J. X., and Howell, S. H. (2010). Endoplasmic reticulum protein quality control and its relationship to environmental stress responses in plants. Plant Cell 22, 2930-2942. doi: 10.1105/tpc.110.078154

Liu, J. X., Srivastava, R., Che, P., and Howell, S. H. (2007). An endoplasmic reticulum stress response in Arabidopsis is mediated by proteolytic processing and nuclear relocation of a membrane-associated transcription factor, bZIP28. Plant Cell 19, 4111-4119. doi: 10.1105/tpc.106.050021

Luo, Q., Lian, H. L., He, S. B., Li, L., Jia, K. P., and Yang, H. Q. (2014). COP1 and phyB physically interact with PIL1 to regulate its stability and photomorphogenic development in Arabidopsis. Plant Cell 26, 2441-2456. doi: $10.1105 /$ tpc.113.121657

Martinez, I. M., and Chrispeels, M. J. (2003). Genomic analysis of the unfolded protein response in Arabidopsis shows its connection to important cellular processes. Plant Cell 15, 561-576. doi: 10.1105/tpc.007609

Mishiba, K., Nagashima, Y., Suzuki, E., Hayashi, N., Ogata, Y., Shimada, Y., et al. (2013). Defects in IRE1 enhance cell death and fail to degrade mRNAs encoding secretory pathway proteins in the Arabidopsis unfolded protein response. Proc. Natl. Acad. Sci. U.S.A. 110, 5713-5718. doi: 10.1073/pnas.121904 7110 
Nagashima, Y., Mishiba, K., Suzuki, E., Shimada, Y., Iwata, Y., and Koizumi, N. (2011). Arabidopsis IRE1 catalyses unconventional splicing of bZIP60 mRNA to produce the active transcription factor. Sci. Rep. 1, 1-10. doi: 10.1038/srep00029

Ning, S. B., Wang, L., and Song, Y. C. (2002). Identification of programmed cell death in situ in individual plant cells in vivo using a chromosome preparation technique. J. Exp. Bot. 53, 651-658. doi: 10.1093/jexbot/53.369.651

Ogawa, N., and Mori, K. (2004). Autoregulation of the HAC1 gene is required for sustained activation of the yeast unfolded protein response. Genes Cells 9, 95-104. doi: 10.1111/j.1365-2443.2004.00704.x

Ozgur, R., Turkan, I., Uzilday, B., and Sekmen, A. H. (2014). Endoplasmic reticulum stress triggers ROS signalling, changes the redox state, and regulates the antioxidant defence of Arabidopsis thaliana. J. Exp. Bot. 65, 1377-1390. doi: $10.1093 /$ jxb/eru034

Ozgur, R., Uzilday, B., Sekmen, A. H., and Turkan, I. (2015). The effects of induced production of reactive oxygen species in organelles on endoplasmic reticulum stress and on the unfolded protein response in Arabidopsis. Ann. Bot. 116, 541-553. doi: 10.1093/aob/mcv072

Ruberti, C., Lai, Y., and Brandizzi, F. (2018). Recovery from temporary endoplasmic reticulum stress in plants relies on the tissue-specific and largely independent roles of bZIP28 and bZIP60, as well as an antagonizing function of BAX-Inhibitor 1 upon the pro-adaptive signaling mediated by bZIP28. Plant J. 93, 155-165. doi: 10.1111/tpj.13768

Schmittgen, T. D., and Livak, K. J. (2008). Analyzing real-time PCR data by the comparative C(T) method. Nat. Protoc. 3, 1101-1108. doi: 10.1038/nprot. 2008.73

Sparkes, I. A., Runions, J., Kearns, A., and Hawes, C. (2006). Rapid, transient expression of fluorescent fusion proteins in tobacco plants and generation of stably transformed plants. Nat. Protoc. 1, 2019-2025. doi: 10.1038/nprot. 2006.286

Srivastava, R., Deng, Y., Shah, S., Rao, A. G., and Howell, S. H. (2013). BINDING PROTEIN is a master regulator of the endoplasmic reticulum stress sensor/transducer bZIP28 in Arabidopsis. Plant Cell 25, 1416-1429. doi: 10.1105/tpc.113.110684

Sun, L., Yang, Z. T., Song, Z. T., Wang, M. J., Sun, L., Lu, S. J., et al. (2013). The plant-specific transcription factor gene NAC103 is induced by bZIP60 through a new cis-regulatory element to modulate the unfolded protein response in Arabidopsis. Plant J. 76, 274-286. doi: 10.1111/tpj.12287

Thordal-Christensen, H., Zhang, Z., Wei, Y., and Collinge, D. B. (1997). Subcellular localization of $\mathrm{H} 2 \mathrm{O} 2$ in plants. $\mathrm{H} 2 \mathrm{O} 2$ accumulation in papillae and hypersensitive response during the barley-powdery mildew interaction. Plant J. 11, 1187-1194. doi: 10.1046/j.1365-313X.1997.11061187.x

Urano, F., Wang, X., Bertolotti, A., Zhang, Y., Chung, P., Harding, H. P., et al. (2000). Coupling of stress in the ER to activation of JNK protein kinases by transmembrane protein kinase IRE1. Science 287, 664-666. doi: 10.1126/ science.287.5453.664

Verbelen, J. P., De Cnodder, T., Le, J., Vissenberg, K., and Baluska, F. (2006). The root apex of Arabidopsis thaliana consists of four distinct zones of growth activities: meristematic zone, transition zone, fast elongation zone and growth terminating zone. Plant Signal. Behav. 1, 296-304. doi: 10.4161/psb.1.6. 3511

Walter, P., and Ron, D. (2011). The unfolded protein response: from stress pathway to homeostatic regulation. Science 334, 1081-1086. doi: 10.1126/ science. 1209038

Watanabe, N., and Lam, E. (2008). BAX inhibitor-1 modulates endoplasmic reticulum stress-mediated programmed cell death in Arabidopsis. J. Biol. Chem. 283, 3200-3210. doi: 10.1074/jbc.M706659200

Weis, C., Huckelhoven, R., and Eichmann, R. (2013). LIFEGUARD proteins support plant colonization by biotrophic powdery mildew fungi. J. Exp. Bot. 64, 3855-3867. doi: 10.1093/jxb/ert217

Williams, B., Kabbage, M., Britt, R., and Dickman, M. B. (2010). AtBAG7, an Arabidopsis $\mathrm{Bcl}-2$-associated athanogene, resides in the endoplasmic reticulum and is involved in the unfolded protein response. Proc. Natl. Acad. Sci. U.S.A. 107, 6088-6093. doi: 10.1073/pnas.0912670107

Woehlbier, U., and Hetz, C. (2011). Modulating stress responses by the UPRosome: a matter of life and death. Trends Biochem. Sci. 36, 329-337. doi: 10.1016/j.tibs. 2011.03.001

Yang, X., Srivastava, R., Howell, S. H., and Bassham, D. C. (2016). Activation of autophagy by unfolded proteins during endoplasmic reticulum stress. Plant J. 85, 83-95. doi: 10.1111/tpj.13091

Yang, Z. T., Wang, M. J., Sun, L., Lu, S. J., Bi, D. L., Sun, L., et al. (2014). The membrane-associated transcription factor NAC089 controls ERstress-induced programmed cell death in plants. PLoS Genet. 10:e1004243. doi: 10.1371/journal.pgen.1004243

Zheng, X., Jin, X., Li, F., Liu, X., Liu, Y., Ye, F., et al. (2017). Inhibiting autophagy with chloroquine enhances the anti-tumor effect of high-LET carbon ions via ER stress-related apoptosis. Med. Oncol. 34:25. doi: 10.1007/s12032-0170883-8

Zonia, L., and Munnik, T. (2008). Vesicle trafficking dynamics and visualization of zones of exocytosis and endocytosis in tobacco pollen tubes. J. Exp. Bot. 59, 861-873. doi: 10.1093/jxb/ern007

Conflict of Interest Statement: The authors declare that the research was conducted in the absence of any commercial or financial relationships that could be construed as a potential conflict of interest.

The reviewer SHH and handling Editor declared their shared affiliation.

Copyright (c) 2018 Guo, Wang, Fan, Wang, Zhu, Tang, Wu, Yang, Shao, Sun, Zhang and $\mathrm{Li}$. This is an open-access article distributed under the terms of the Creative Commons Attribution License (CC BY). The use, distribution or reproduction in other forums is permitted, provided the original author(s) and the copyright owner are credited and that the original publication in this journal is cited, in accordance with accepted academic practice. No use, distribution or reproduction is permitted which does not comply with these terms. 